\title{
A Review on the Current Status of Icing Physics and Mitigation in Aviation
}

\author{
Masafumi Yamazaki, Aleksandar Jemcov and Hirotaka Sakaue *(D)
}

Citation: Yamazaki, M.; Jemcov, A.; Sakaue, H. A Review on the Current Status of Icing Physics and Mitigation in Aviation. Aerospace 2021, 8, 188 https://doi.org/10.3390/

aerospace 8070188

Academic Editor: Qiang Zhang

Received: 6 June 2021

Accepted: 25 June 2021

Published: 14 July 2021

Publisher's Note: MDPI stays neutral with regard to jurisdictional claims in published maps and institutional affiliations.

Copyright: (C) 2021 by the authors. Licensee MDPI, Basel, Switzerland. This article is an open access article distributed under the terms and conditions of the Creative Commons Attribution (CC BY) license (https:// creativecommons.org/licenses/by/ $4.0 /)$.
Department of Aerospace and Mechanical Engineering, University of Notre Dame, Notre Dame, IN 46556, USA; myamazak@nd.edu (M.Y.); ajemcov@nd.edu (A.J.)

* Correspondence: hsakaue@nd.edu; Tel.: +1-574-631-4336

\begin{abstract}
Icing on an aircraft is the cause of numerous adverse effects on aerodynamic performance. Although the issue was recognized in the 1920s, the icing problem is still an area of ongoing research due to the complexity of the icing phenomena. This review article aims to summarize current research on aircraft icing in two fundamental topics: icing physics and icing mitigation techniques. The icing physics focuses on fixed wings, rotors, and engines severely impacted by icing. The study of engine icing has recently become focused on ice-crystal icing. Icing mitigation techniques reviewed are based on active, passive, and hybrid methods. The active mitigation techniques include those based on thermal and mechanical methods, which are currently in use on aircraft. The passive mitigation techniques discussed are based on current ongoing studies in chemical coatings. The hybrid mitigation technique is reviewed as a combination of the thermal method (active) and chemical coating (passive) to lower energy consumption.
\end{abstract}

Keywords: aircraft icing; anti-icing; deicing; icing physics; icing mitigation; icephobic coating; heating; icing wind tunnel; power consumption; ice crystal icing

\section{Introduction}

Aircraft icing has always been a hazardous issue since it was recognized in the 1920s because it causes degradation in the aerodynamic performance and malfunction of essential flight instruments [1]. The primary focus of aircraft icing research has been on ice accretion on wings for its serious adverse consequences. When icing occurs on a wing, the change in airfoil shape results in a decrease in lift and an increase in drag, leading to potentially fatal accidents [2]. Historical icing studies were documented several times in the literature [1-3]. The early stages of icing research were carried out mainly by experiments geared toward understanding icing physics and the development of icing mitigation techniques [4]. In the 1970s, the development of numerical simulations for aircraft icing began growing. The motivation of the simulation was reducing the cost and lowering the risk of accidents during the certification process for icing mitigation devices. Since then, experimental and numerical investigation have been used side by side to establish more accurate icing simulation tools.

From a meteorological perspective, initial icing research focused on icing caused by small water droplets up to $40 \mu \mathrm{m}$ in diameter, often referred to in Appendix C of Part 25 of Title 14 in the U.S. Code of Federal Regulations [5]. However, an ATR-72 accident in Roselawn in 1994 [6] revealed the need for research expertise beyond the water-droplet-size envelope provided in Appendix C. The National Transportation Safety Board concluded that the accident was caused by supercooled water droplets, which were up to $2000 \mu \mathrm{m}$ in diameter. Therefore, the FAA introduced new regulations as Appendix O, which describes meteorological conditions with potential for icing with water droplet diameter up to approximately $2000 \mu \mathrm{m}$ in diameter. Since the 1990s, icing caused by water droplets larger than $40 \mu \mathrm{m}$ in diameter has been referred to as supercooled large droplet (SLD) icing. It has remained a challenging topic for aircraft icing researchers. In addition to SLD icing, 
the 1990s saw a significant increase in the interest in jet engine icing $[7,8]$. Engine icing is often referred to as ice crystal icing since it is considered to be caused by ice crystals rather than the supercooled droplets that cause icing on wings. Meteorological conditions for the ice crystal icing were documented as Appendix D of Part 33 of Title 14 in the U.S. Code of Federal Regulations [9] and Appendix P of European Union Aviation Safety Agency (EASA) CS-25 [10]. For the ice crystal icing, knowledge of the underlying physics is currently limited.

There are two different concepts for icing mitigation: anti-icing and deicing [4]. Antiicing techniques are designed to completely prevent ice from forming on an aircraft surface, while deicing techniques remove the accreted ice before it causes significant adverse effects [4]. Nowadays, several mitigation methods are available and used for aircraft. However, there is still considerable research towards optimizing the established methods and developing new icing mitigation systems.

It is beneficial to review the forefront of icing physics and icing mitigation techniques to clarify the remaining challenges for icing research. From time to time, aircraft icing research is reviewed by several researchers. Previous reviews discussed the icing physics on fixed-wing aircraft and currently in-use icing mitigation techniques. Gent in 2000 [11] and Cebeci in 2003 [12] focused on the status of calculation techniques for ice accretion prediction, aerodynamic performance degradation, and ice mitigation system performance. Lynch and Khodadoust [13] reviewed test results for aerodynamic performance and control degradation, taking into account several types of ice accretions on a wing. Bragg et al. [3] provided the history of icing research from the beginning and reviewed iced airfoil aerodynamics based on flow field physics. Cao et al. reviewed icing research in general, from meteorological icing conditions to the analysis of actual flight accidents [14]. In terms of the icing mitigation techniques, Thomas et al. [4] introduced the available mitigation methods at the time of their publication.

This review article aims to summarize the current knowledge on icing physics and mitigation techniques for aircraft. The research status of icing physics is provided in three parts. The first part focuses on the icing on a fixed wing, which has a long history with numerous mitigation techniques. The second part is given for rotor icing, which has more complicated icing physics than a fixed wing. The last part presents the engine icing problem. The icing mitigation technique begins with discussing active mitigation methods such as pneumatic boots and hot-air anti-icing systems currently used on commercial aircraft. The review then moves toward discussing passive mitigation techniques currently under development. The hybrid mitigation technique combining the active and passive mitigation methods is introduced as a new approach.

\section{Icing Physics}

Icing research began with studying icing on fixed wings which can be considered as a two-dimensional phenomenon. On rotors, the three-dimensional effects of the flow field around the airfoil make the icing phenomena more complicated than that of the fixed wing. These two research topics have long histories, and so several simulation codes for ice accretion prediction are available. Additionally, recent experimental research has been conducted to improve the accuracy of the predicted ice accretion shape of those simulation codes. Therefore, both experimental and numerical investigations are presented along with the improvements in the icing simulation techniques.

Engine icing is discussed in the last part of this section. This topic has garnered significant attention since the 2000s. Compared to icing on airfoils, the knowledge of engine icing is limited [15]. Recent efforts have been devoted to a better understanding of the icing phenomenon itself. Current findings are summarized to accelerate future exploration.

\subsection{Fixed Wing Icing}

The impact of supercooled water droplets causes the icing on a fixed wing. Depending on meteorological conditions such as temperature, airspeed, and the size of water droplets, 
ice accretion is formed as rime, glaze, and mixed ice. Rime ice is likely to be created when the temperature is low enough for the entire droplets to freeze entirely upon impact. On the other hand, when water droplets freeze only partially upon the impact (for instance, when the temperature is lower than, yet close to, $0^{\circ} \mathrm{C}$ ), glaze ice is formed on the surface. Mixed refers to the coexistence of rime and glaze ice. [14] These ice formations can be seen from icing caused by supercooled water droplets up to $40 \mu \mathrm{m}$ in diameter. However, if the droplet diameter exceeds $40 \mu \mathrm{m}$, known as supercooled large droplets (SLDs), further study is necessary to understand the features of ice accretion. In the following, recent icing research is presented after introducing current icing simulation schemes.

Icing simulation tools became available in the 1990s [16]. The initial function of those tools was to predict the ice shape on a two-dimensional airfoil from the icing environmental conditions. Numerous discussions in the literature explain how those tools calculate ice shapes $[4,13,17]$. A conventional icing simulation starts from determining the water collection efficiency, which represents how often water droplets impinge on the airfoil. This calculation often refers to the droplet trajectory calculation [11]. In the droplet trajectory calculation, there are two ways to consider the size of water droplets [13]. One way is to use a droplet diameter distribution, such as Langmuir D distribution [18]. Another considers a single droplet diameter, referred to as median volumetric diameter [13]. Once the number of impinging droplets is known, the energy and mass balance within a control volume on the airfoil surface is considered, as illustrated in Figure 1. The energy balance model based on thermodynamics for an unheated surface was proposed by Messinger [19]. Mass conservation is considered based on the amount of liquid water in a control volume. The mass coming into a control volume consists of (1) impinging water droplets, $\dot{m}_{i m p}$, and (2) water flow from the adjacent segment in the upstream, $\dot{m}_{r_{i n}}$. In contrast, the mass going out is divided into (1) ice accretion, $\dot{m}_{i c e} ;(2)$ water flow to the downstream, $\dot{m}_{r_{o u t}} ;$ and (3) evaporation, $\dot{m}_{e}$.

$$
\dot{m}_{i m p}+\dot{m}_{r_{i n}}=\dot{m}_{i c e}+\dot{m}_{r_{o u t}}+\dot{m}_{e}
$$

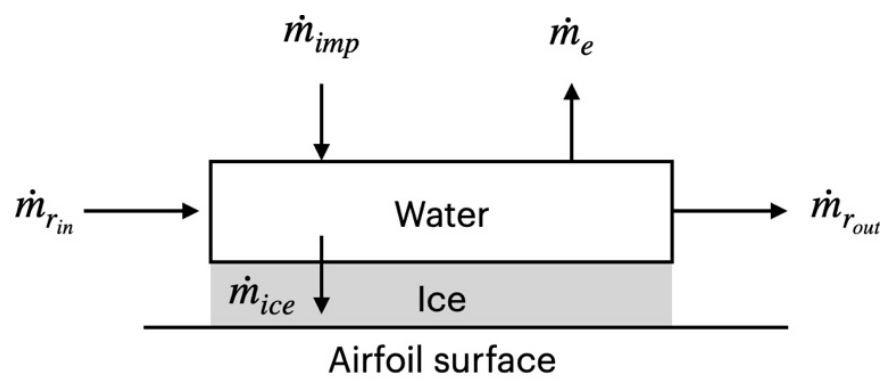

Figure 1. Schematic of parameters for the mass conservation in Messinger model.

By introducing the freezing fraction, $f$, into the mass balance, the mass of the ice accretion and water flow to the downstream can be expressed as

$$
\begin{gathered}
\dot{m}_{i c e}=f\left(\dot{m}_{i m p}+\dot{m}_{r_{i n}}-\dot{m}_{e}\right) \\
\dot{m}_{r_{\text {out }}}=(1-f)\left(\dot{m}_{i m p}+\dot{m}_{r_{i n}}-\dot{m}_{e}\right)
\end{gathered}
$$

The freezing fraction represents the number of impinging droplets that freeze in a given control volume compared to the total incoming water mass. It is used to define the type of accreted ice depending on its value. When $f$ is 1.0 , the accreted ice is classified as rime ice. In contrast, when $f$ is close to 0 , the ice is classified as glaze ice. 
For energy conservation, contributing energy terms in the control volume are (1) $\dot{Q}_{\text {conv }}$ : convective heat, (2) $\dot{Q}_{\text {imp }}$ : kinetic energy of water droplets, (3) $\dot{Q}_{\text {latent }}$ : latent heat, and (4) $\dot{Q}_{\text {sensible }}$ : sensible heat. By taking all these terms, a heat balance can be expressed as

$$
\dot{Q}_{\text {conv }}+\dot{Q}_{\text {imp }}+\dot{Q}_{\text {latent }}+\dot{Q}_{\text {sensible }}=0
$$

$\dot{Q}_{\text {conv }}$ and $\dot{Q}_{i m p}$ are defined as follows:

$$
\begin{gathered}
\dot{Q}_{\text {conv }}=h_{\text {conv }}\left(T_{\text {rec }}-T_{b}\right) \\
\dot{Q}_{\text {imp }}=\frac{1}{2} \dot{m}_{\text {imp }} V_{i m p}{ }^{2}
\end{gathered}
$$

where $h_{\text {conv }}$ is the convective heat transfer coefficient, $T_{\text {rec }}$ is the airflow recovery temperature, $T_{b}$ is the balance temperature of the control volume, and $V_{i m p}$ is the velocity of impinging droplets. For $\dot{Q}_{\text {latent }}$, the latent heat of freezing, $\dot{Q}_{\text {freeze }}$, and the latent heat of evaporation or sublimation, $\dot{Q}_{e s}$, contribute as follows:

$$
\begin{gathered}
\dot{Q}_{\text {latent }}=\dot{Q}_{\text {freeze }}+\dot{Q}_{e s} \\
\dot{Q}_{\text {freeze }}=L_{f} f\left(\dot{m}_{\text {imp }}+\dot{m}_{r_{i n}}\right) \\
\dot{Q}_{e s}=-L_{e s} \dot{m}_{e s}
\end{gathered}
$$

where $L_{f}$ and $L_{e s}$ are the latent heat of freezing and evaporation or sublimation per kilogram, respectively. $\dot{Q}_{\text {sensible }}$ changes with time and temperature. For the ice accretion process in the control volume, it is assumed that the temperature of incoming water increases to the freezing temperature, $T_{f}$, followed by the ice and unfrozen water reaching the balance temperature, $T_{b}$. Since the incoming water is due to droplet impingement and water flow from the adjacent segment in the upstream, the terms associated with heating are

$$
\begin{gathered}
\dot{Q}_{s, i m p}=\dot{m}_{i m p} C_{p, w}\left(T_{i m p}-T_{f}\right) \\
\dot{Q}_{s, r_{i n}}=\dot{m}_{r_{i n}} C_{p, w}\left(T_{r_{i n}}-T_{f}\right)
\end{gathered}
$$

where $C_{p, w}$ is the specific heat of the water. When the ice and unfrozen water reach the balance temperature,

$$
\begin{gathered}
\dot{Q}_{s, \text { ice }}=\dot{m}_{i c e} C_{p, i}\left(T_{f}-T_{b}\right) \\
\dot{Q}_{s, r_{\text {out }}}=\dot{m}_{r_{\text {out }}} C_{p, w}\left(T_{f}-T_{b}\right)
\end{gathered}
$$

Finally, sensible heat can be obtained from the following equation:

$$
\dot{Q}_{\text {sensible }}=\dot{Q}_{s, \text { imp }}+\dot{Q}_{s, r_{i n}}+\dot{Q}_{s, i c e}+\dot{Q}_{s, r_{\text {out }}}
$$

By substituting Equations (2) and (3) into Equation (4), the freezing fraction, $f$, and the balance temperature, $T_{b}$, can be derived. When $f$ is derived for every segment on the airfoil, $\dot{m}_{\text {ice }}$ can be obtained [20].

With considerable efforts devoted to developing icing simulations for a fixed wing, many reports $[16,21,22]$ documented that those simulation results showed good agreements with ice shape from experimental data for rime ice accretions. However, there remains the demand for improvement in glaze ice conditions and supercooled large droplet (SLD) icing, as mentioned in previous review papers [3,11,13]. Among the parameters given in Equations (1) and (4), it is not fully understood which parameters are not adequately modeled. Although under those circumstances, researchers are working to understand 
the effect of droplet parameters and surface roughness on the accuracy of aircraft icing simulations.

\section{(1) Droplet Impact}

The droplet trajectory in conventional icing simulations was based on the assumption that water droplets do not deform and coalesce before the impact, nor do they rebound and splash upon impact [23]. However, for SLD icing, since the sizes of water droplets are large, the droplets may deform or even break up due to aerodynamic forces. In this case, the assumptions made in the early stage of aircraft icing simulation no longer hold. There were a large number of investigations on droplet deformation and breaking up in the field, such as fuel injection and aerosol atomization. In the aerospace industry, Tan et al. [24] developed a numerical model on droplet deformation and breakup near the leading edge of an airfoil based on their literature review. They reported that the droplets potentially break up where the pressure gradient is severe. Since this numerical study was carried out with limited experimental data, Vargas and Feo experimentally investigated the droplet deformation and breakup further [25]. Specific attention was paid to the value of the critical Weber number for droplet breakup conditions in the air. Here, Weber number is defined as follows:

$$
W e=\frac{\rho_{a} V^{2} d}{\sigma}
$$

where $\rho_{a}$ is the density of the air, $V$ and $d$ are the velocity and diameter of the droplet, and $\sigma$ is the surface tension between the air and water. As concluded in [24], the critical Weber number to describe the droplet breakup greatly differed depending on the experimental facilities and relative droplet-air velocity. For example, the current version of LEWICE, the icing simulation provided by NASA, added the empirical relationship reported in [26], where the critical Weber number was 13. While LEWICE treats the droplet trajectories in the Lagrangian formulation, another icing simulation, FENSAP-ICE, implemented the Pilch and Erdman model [27] for droplet breakup in the Eulerian formulation [28,29]. The critical Weber number in [27] was defined as follows:

$$
W e_{\text {critical }}=12\left(1+1.077 O h^{1.6}\right)
$$

where $O h$ is the Ohnesorge number defined as

$$
O h=\frac{\mu_{d}}{\sqrt{d \rho_{d} \sigma_{d}}}
$$

Here, $\mu_{d}$ is the droplet viscosity, $d$ is the droplet diameter, $\rho_{d}$ is the droplet density, and $\sigma_{d}$ is the droplet surface tension.

In addition to the droplet breakup, as mentioned in [30], Papadakis et al. observed that there were small droplets that traveled against the airflow near the leading edge of NACA0012 airfoil in the case of SLDs. Those droplets may bounce back or break up upon impact on the airfoil surface, and thus the assumption that all impinged water droplet stays on the surface does not hold. Since then, droplet impingement dynamics have gained significant attention to correct the deficiency in the assumption. The phenomenon of the droplet bouncing back or breaking up upon the impingement has been referred to as the droplet-wall interaction, and explorations to understand the underlying physics are still ongoing. For droplet splashing, five critical parameters need to be determined: the splashing threshold, splashed droplet diameters, splashed droplet velocities, splashing angles, and the mass of sprayed droplets [31]. The fundamentals of the splashing behaviors were investigated mainly outside aerospace fields [32-35], and there exists a large number of models related to the aforementioned splashing parameters. In this review, splashing models which are used in the current icing simulation tools are highlighted.

The volume of fluid (VOF) or momentum of fluid (MOF) methods are known to simulate droplet splashing dynamics with a high degree of accuracy [36-38]. These methods 
are capable of describing the time-changing deformation and breakup of a single droplet during splashing. However, their computational costs are considerably high since the mesh size is smaller than splashed droplets. If they were implemented into the aircraft icing simulation, the overall computational cost exceeds current computational capabilities. Therefore, current icing simulation codes utilize semiempirical models. These models are developed to derive the postimpact droplet properties, such as the number of splashed droplets, velocity, and the size of sprayed droplets, directly from the preimpact droplet properties (Figure 2). Since semiempirical models do not consider the complicated physics when water droplets come in contact with the surface, those models can include the effect of droplet splashing in SLD conditions with relatively low computational cost [30].

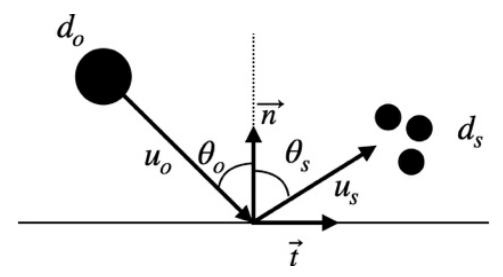

Figure 2. Main splashing parameters related to the numerical models.

The function of those semiempirical models in droplet impingement is to correct the mass of incoming water droplets into a control volume in Equation (1) by considering the mass loss of water due to splashing [30]. To calculate the mass loss, those models are required to provide the properties of the postimpact droplets and the threshold for the occurrence of droplet splashing. Most models use nondimensional numbers such as Weber number, Ohnesorge number, and Reynolds number to deal with variations in velocities and diameters of impinging droplets. Unlike the Weber number used to describe the droplet breakup in the air, the Weber number for splashing is defined as follows:

$$
W e=\frac{\rho_{d} V^{2} d_{0}}{\sigma}
$$

where $\rho_{d}$ is the density of the droplet. Ohnesorge number is the same as Equation (17), and Reynolds number is described as follows:

$$
R e=\frac{\rho_{d} d_{0} V}{\mu}
$$

For $V$ in Equations (18) and (19), the normal component of the velocity of the impinging droplet with respect to the surface, $V=u_{0} \cos \theta_{0}$, is used (Figure 2). These models were developed originally in the spraying industry, and established models were introduced to aircraft icing simulations [39]. Most investigations were conducted by single droplet impingement experiments [39]. In the case of aircraft icing, water droplets may impinge at speeds up to approximately $100 \mathrm{~m} / \mathrm{s}$ on a dry or wet surface. The surface roughness and the temperatures of the droplet and the surface may also vary in aircraft icing. The accuracy in the prediction of ice shape from a simulation partially depends on selecting an appropriate model to describe various splashing phenomena.

Mundo et al. [40] provided the required description for the threshold and postimpact droplet properties. This model's distinctive feature is that it considers the viscosity of the impinging droplet for the threshold. They defined the threshold for the splashing phenomenon based on Weber and Reynolds numbers of an impinging droplet as follows:

$$
K_{M}=\left[W e e^{\frac{1}{2}}\right]^{\frac{1}{2}}=\left[\frac{\rho_{d}^{3} d_{0}^{3} u_{n, 0}{ }^{5}}{\sigma^{2} \mu_{d}}\right]^{\frac{1}{4}}
$$

where $\rho_{d}$ is the density of the droplet, $d_{0}$ is the diameter of the droplet, $u_{n, o}$ is the normal velocity of the droplet with respect to the impinging surface, $\sigma$ is the surface tension, and 
$\mu_{d}$ is the viscosity of the droplet. The splashing occurs when $K_{M}>57.7$. However, this criterion did not include the effect of surface roughness. For the splashing threshold on a wetted surface, Cossali et al. [41] experimentally determined the following relationship based on Weber and Ohnesorge numbers:

$$
\mathrm{WeOh} h^{-0.4}<2100+5880 \delta^{1.44}
$$

where $\delta$ is the nondimensional film thickness defined as the ratio between the film thickness and droplet diameter. The determining parameter on the left-hand side in Equation (18) is often called the Cossali parameter, $K_{C}$. Later, Trujillo et al. [42] reviewed existing splashing models, including the Mundo and Cossali models. They provided a combined splashing model that considers the surface roughness and water film thickness on the wetted surface. From this model, splashing on a dry surface occurs when

$$
K_{C, d r y}=W e O h^{-0.4}<180 R^{-0.35}
$$

where $R$ is the normalized surface roughness. They also reported the correlation in the Cossali parameter between dry and wetted surfaces as follows:

$$
K_{C, \text { wet }} \cong 3.0 K_{C, d r y}=540 R^{-0.35}
$$

While the aforementioned splashing models were derived from experimental results, those investigations were performed at lower velocities than the conditions seen in aircraft icing. When those models were implemented into aircraft icing simulations, researchers had to rely on extrapolated data from experimental results. To make those models more suitable for aircraft icing, researchers modified those models by implementing them into icing simulation codes and comparing the calculated collection efficiency with water impingement results conducted in icing wind tunnels. Wright [43] implemented the Mundo model into LEWICE and modified the description for the splashing threshold. He defined the threshold using the velocity normal to the airfoil surface:

$$
K_{L}=\sqrt{K_{M}}\left\{\frac{3}{2}\left(\frac{L W C}{\rho_{d}}\right)^{\frac{1}{3}}\right\}^{-\frac{3}{8}}>20
$$

where $L W C$ is the liquid water content in the freestream. For the diameters, mass, and velocity of the splashed droplets, he proposed the following descriptions using the Mundo parameter defined in Equation (20):

$$
\begin{gathered}
\frac{d_{s}}{d_{0}}=8.72 e^{-0.0281 K_{M}} \\
\frac{m_{s}}{m_{0}}=0.7\left[1-\sin \theta_{0}\right]\left[1-e^{-0.0092\left(K_{L}-200\right)}\right] \\
\frac{u_{t, s}}{u_{t, 0}}=1.075-0.0025 \theta_{0} \\
\frac{u_{n, s}}{u_{n, o}}=0.3-0.002 \theta_{0}
\end{gathered}
$$

where variables $d, m, u$, and $\theta$ denote the diameter, mass, velocity, and impingement angle of the droplet while subscriptions $s, o, t$, and $n$ represent the secondary (splashed) droplet, original (before impact) droplet, tangential component, and normal component with respect to the impinging surface, respectively (Figure 2). Honsek [44] proposed an Eulerian formulation of a splashing model based on the Trujillo and Lee model. The proposed model was calibrated by comparing the experimental results from [45] with simulated results obtained by implementing the model into DROP3D, a module calculating the droplet impingement characteristics used in FENSAP. Since this model was established 
in an Eulerian frame, the modification was made only in the mass loss expression, $f_{m}$, due to the splashing.

$$
f_{m}=\frac{m_{s}}{m_{0}}=3.8 \frac{1.0-e^{-0.85\left(K^{\prime}-17\right)}}{\sqrt{K^{\prime}}}
$$

where $K^{\prime}=0.45^{\frac{3}{8}}\left(O h^{-\frac{2}{5}} \mathrm{We}\right)^{\frac{5}{16}}$.

While splashing models developed in the early stage relied on single droplet impingement experiments, most of the models were developed based on comparisons between experimental results of the droplet collection efficiency on airfoils and those produced by aircraft icing simulations in which splashing models were implemented. Although several studies in the literature found that those correlations perform well in aircraft icing simulations, the performance of these models in high-speed flows, such as above 30 $\mathrm{m} / \mathrm{s}$, is lacking. Detailed information on high-speed droplet impingement may enable the consideration of additional effects such as the interaction between impinging and splashed droplets.

\section{(2) Surface Roughness}

The calculation of the freezing fraction, $f$, is another factor that impacts the accuracy of an icing simulation. Traditional simulations took the control volume approach using the Messinger model shown in Section 2.1 to compute the freezing fraction. This model was developed by considering the heat balance between the air, water droplets, and the airfoil with or without ice. It was further extended by Myers [46] by including air compressibility effects. Of the several parameters related to this heat balance calculation, the surface roughness of the accreted ice has been the most critical factor. This is because surface roughness changes flow characteristics such as boundary layer dynamics that result in changes in the local collection efficiency, convective heat transfer, and consequently, the final ice shape.

Olsen and Walker [47] reported a smooth surface around the leading edge for ice roughness in glaze ice conditions followed by a rough region downstream. Shin [48] conducted qualitative ice roughness measurements and boundary-layer measurements to investigate the effects of the iced surface roughness on the boundary layer. It was confirmed that there was a distribution of irregular surface roughness at the beginning of ice accretion, and the roughness eventually reached a constant value. Anderson and Shin [49] established the correlation between roughness characteristics and nondimensional terms such as the freezing fraction, $\mathrm{f}$, and the accumulation parameter. Those correlations were implemented into simulation codes to predict the maximum roughness height. However, Anderson et al. [50] also revealed that those single parameters were not sufficient to describe the ice roughness in glaze ice conditions.

Recent research has aimed to achieve better roughness prediction schemes [51] and model development to compute the heat transfer coefficient [52-54]. If topics were to better model actual icing physics, experimental and numerical investigations for heat transfer would be needed to account for the actual ice roughness rather than the sand grain roughness used in conventional icing codes.

The ice roughness measurements were traditionally conducted by digitized pencil tracing, ice shape molding, and multiangle photography [55]. Lee et al. developed the laser-based 3D scanning method [56] to resolve the roughness better. This measurement technique leads to developing the statistical characterization of ice roughness by adopting the self-organized map approach [57-59]. More details on those roughness measurement techniques can be found in [59].

\subsection{Rotor Icing}

Rotorcrafts such as helicopters are operated for a long time at altitudes below $6000 \mathrm{~m}$, where supercooled water droplets may exist in clouds [60]. The airfoil of rotorcraft is generally smaller in size than that of a fixed-wing aircraft, which means water droplets are 
more likely to impinge since the collection efficiency increases when the leading-edge radius decreases, as reported in [61]. Therefore, helicopters are more susceptible to icing [62]. The icing occurs on the forward front of rotors. This leads to unbalanced loads between the blades, which excites certain vibrational modes. One of the distinct differences between icing on rotors and icing on fixed wings is the existence of the centrifugal forces acting on the accreted ice and water film on the rotor surface [63]. Simulating this remains a challenge for current three-dimensional icing simulations. Starting with the explanation of the calculation procedure for the three-dimensional icing simulation, recent advancements in research related to the consideration of centrifugal forces are presented in the following section.

The seriousness of the icing problem on rotors was already recognized in 1977 [64]. In the early stages, icing experiments were conducted as in-flight tests where test results heavily depended on meteorological conditions. According to a report from the U.S. Army [65], they had $0.29 \mathrm{~h}$ of testing time per day on average. Due to the high cost and safety concerns for in-flight icing tests, rotor icing experimental facilities on the ground were established in several regions. The National Research Council Canada constructed a spray rig outside, producing water droplets between 20 and $60 \mu \mathrm{m}$ in diameter. The U.S. Air Force has McKinley Climatic Chamber in Florida [66]. The Pennsylvania State University has a smaller test stand in the Adverse Environment Rotor Test Stand (AERTS) where rotors up to $4.5 \mathrm{ft}$ in diameter fit in the test section (Figure 3) [67].
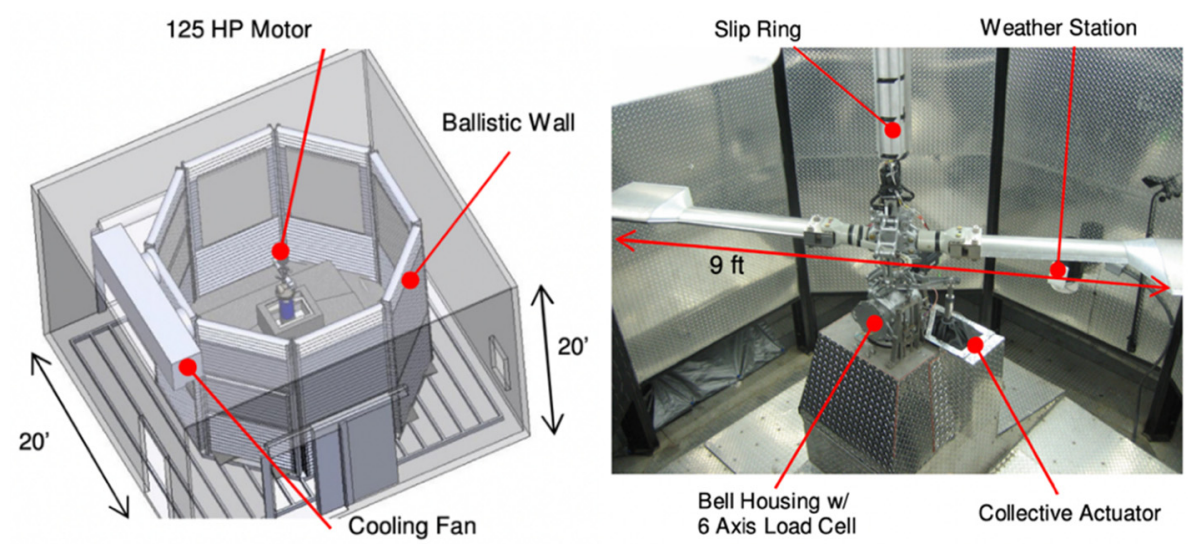

Figure 3. Overview of AERTS (left) and test stand (right) (Reproduced with permission from Palacios, J.L. [68]).

Based on experimental data obtained in icing test facilities, three-dimensional icing simulation codes have been developed, such as LEWICE 3D [69], FENSAP-ICE [70], and ONERA 3D [71]. Even though there are differences among those simulation codes, the calculation schemes are similar to conventional two-dimensional icing simulations. Instead of the two-dimensional flow field calculation, most simulation codes employ the three-dimensional flow field calculation. The calculation of the ice accretion is made on a particular blade section in a way similar to the conventional two-dimensional icing simulation. After calculating the ice shape at each radial position, the flow field around the iced rotor is recalculated in three dimensions. This loop continues until the designated iterations are completed [72].

Due to the fruitful knowledge from two-dimensional icing simulations, current three-dimensional icing simulations have icing prediction capabilities. For instance, Narducci et al. [72] investigated the accuracy of the predicted ice shape by LEWICE 3D by comparing the experimental results obtained during the Helicopter Icing Flight Test program carried out by NASA and the U.S. Army [73]. However, it does not take into account the influence of the centrifugal forces [63]. Accreted ice on a rotor experiences centrifugal forces, unlike fixed wings. That force is more significant close to the tip, and ice can be detached from the rotor when the centrifugal force overcomes ice adhesion force on 
the surface. This phenomenon is called ice shedding. It was experimentally confirmed by Busch and Bragg [74].

With the establishment of the AERTS Facility, Brouwers et al. [75] developed the ice shedding model using the ice shape predicted by LEWICE. The model was validated with the propeller icing experiments for a hovering rotor. The ice shedding time and location prediction were within $25 \%$ of the experimental results (Figure 4 ).

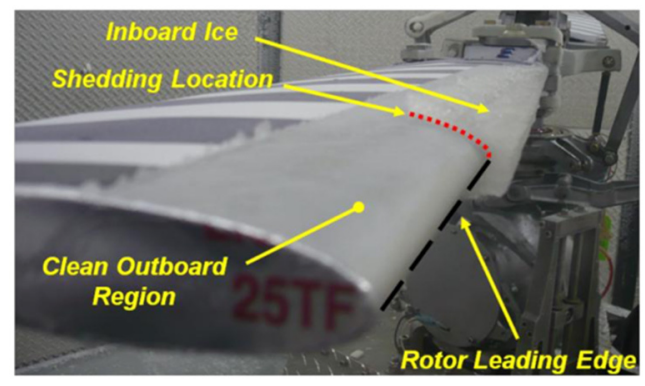

Figure 4. Ice shedding observed in [75] (Reproduced with permission from Brouwers, E).

For more detailed ice shedding mechanisms, Zhan et al. [76,77] developed a threedimensional finite element method code to simulate crack propagation in the accreted ice. The ice shape was generated by FENSAP-ICE. The crack propagation was determined based on the stress acting on the ice, assuming that the direction of the crack was perpendicular to the maximum principal stress direction. While their model provided great insight into the details of ice shedding events, it has not been validated against experimental results since there exists little available data.

In addition to the centrifugal force acting on the accreted ice and causing ice shedding, its effect on the water film is also essential to predict the ice shape accreting on rotors more accurately. In the case of icing on a fixed wing, the motion of the water film is in the chordwise direction due to aerodynamic shear stress. However, in icing on rotors, the centrifugal force on the water film causes motion in the spanwise direction. Zhao et al. [78] developed a numerical method to predict the ice accretion on rotors concerning the centrifugal force acting on the water film. Wang and Zhu [79] also developed a numerical simulation of ice accretion on rotors with this centrifugal force consideration. They concluded that the ice thickness at close to the stagnation point increased while it decreased at the frozen limit. Kelly et al. [80] proposed a numerical approach to calculate the performance degradation of rotors. Their method included the water film motion toward the spanwise direction. When compared with experimental results provided in [75], their method improved the accuracy in terms of predicting the ice shape.

Although the accuracy of the ice accretion prediction on rotors has been improved by considering the centrifugal force, the quantitative evaluation of the accuracy has not been investigated since the available experimental results are limited, especially for the water film movement. Researchers have continued to study these problems over the years. However, continuous efforts are required for further improvement in the rotor icing simulation.

\subsection{Engine Icing}

A large number of unexpected power losses were reported from commercial aircraft at altitudes higher than 22,000 ft near thunderstorms [7]. In those regions, water was expected to exist in the form of ice particles. Mason et al. [7] hypothesized that those ice particles contributed to ice accretion inside the engine (Figure 5). Here, engine icing is often called ice crystal icing. In their hypothesis, both liquid and ice particles cause ice accretion inside an engine. Liquid water on the surface inside the engine would slow down ice particles, enabling heat to be removed from the surface. When the surface temperature decreases to the freezing point, ice can begin to accrete. In this situation, only the surface temperature is required to reach the freezing point, which means that this 
accretion might happen even when the local air temperature is above $0{ }^{\circ} \mathrm{C}$. This unique ice accretion occurs on the static component in the low-pressure compressor and eventually leads to rollback due to the blockage. In addition, this accreted ice can cause damage to compressor blades, rotor blade tip rubs, vibration, surge, and flameout as it is shed from the surface [81]. While the development of analytical models is required to support the engine certification process as well as next-generation engine design, this kind of icing physics has not been well understood since there exists a limited number of ground-test facilities that can reproduce the ice particle ingestion into the aircraft engine at cruise conditions [8]. To better understand ice crystal icing, numerous research efforts have been conducted based on the hypothetical mechanism proposed in [7]. The focus of each research effort is on a specific part of the total process of ice crystal icing. Ongoing research can be seen for (1) measurement of the ice crystal icing conditions and (2) a numerical approach.

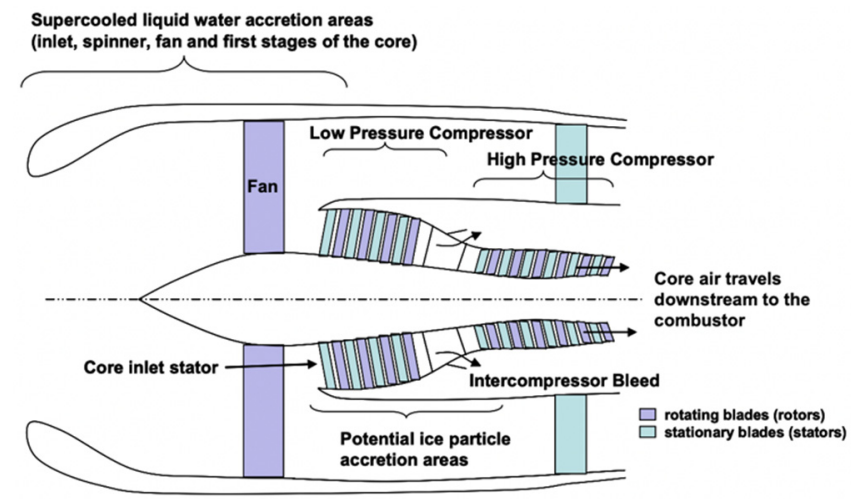

Figure 5. Structure of the engine and potential ice accretion area (reproduced from [7]).

(1) Measurement on Ice Crystal Icing

To better understand the icing physics of ice crystal icing, environmental conditions in the engine core should be first characterized. In addition to the icing parameters discussed in Sections 2.1 and 2.2, such as air temperature, airspeed, mean volumetric diameter of liquid water droplets (MVD), and liquid water content (LWC), the total water content (TWC) should also be considered for ice crystal icing. TWC is the mass of water droplets and ice particles contained in $1 \mathrm{~m}^{3}$ of the air. It is expressed as the sum of $L W C$ and the ice water content (IWC), and it is used in the form of the melting ratio, $L W C / T W C$, since liquid water is the key for ice accretion. Besides TWC, the wet-bulb temperature in the engine is considered in ice crystal icing. It is a function of the temperature, pressure, and humidity of the air [15]. As previous works revealed [82-84], this temperature determines melting and water evaporation and affects ice accretion behavior in the engine. When the wet-bulb temperature exceeds $0{ }^{\circ} \mathrm{C}$, the melting ratio becomes higher, resulting in slush ice formation. The slushy ice may cause physical damage to compressor blades if it is removed from the surface. In contrast, solid ice forms on the surface when the wet-bulb temperature is below the freezing point. If the ice grows large enough to block the airflow, then flameout may occur [7].

During the establishment of the ground-test facilities for studying ice crystal icing, research challenges seemed to arise from the characterization of TWC conditions. Van Zante et al. [85] measured TWC created in an altitude engine research test facility at NASA's Glenn Propulsion System Laboratory using the isokinetic probe (Figure 6) and multi-hot-wire probe. The isokinetic probe measures TWC by evaporating all hydrometeors it captures [86]. 


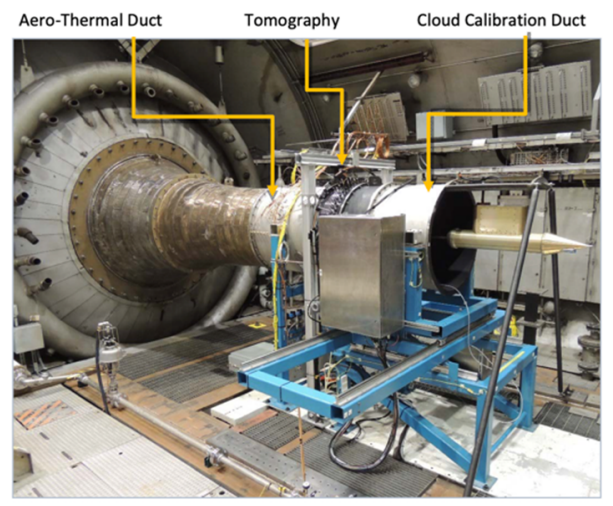

Figure 6. Cloud condition calibration test setup using the isokinetic probe (obtained from [85]).

It was revealed by Davison et al. [87] that the isokinetic probe can be reliable for high TWC measurement. The multi-hot-wire probe is equipped with several strings. It measures TWC based on the power required to keep the wire temperatures constant. While those two instruments showed similar measurements of $L W C$ in the supercooled liquid cloud condition (no ice crystals present), the multi-hot-wire probe recorded lower LWC values in ice crystal cloud conditions at approximately 60\% [9]. To achieve more accurate measurements of TWC, analysis based on the existing experimental results and the development of other measurement devices is currently ongoing [88].

(2) Numerical Models of Ice Crystal Icing Physics

In addition to researchers' efforts to determine essential factors in icing conditions such as TWC, numerical simulations to predict two-dimensional ice accretion due to ice crystal icing have been developed (GlennIce from NASA [89], IGLOO2D from ONERA [90], FENSAP-ICE from ANSYS [91], and ICICLE from University of Oxford [92]). The primary strategy in the development of ice crystal icing simulations is to introduce the unique features of ice crystal icing into conventional icing simulations of a supercooled water droplet. Each simulation is mainly based on the same process as for the icing simulation on the fixed wing discussed in Section 2.1: (1) airflow around the ice accretion site, (2) droplet and ice particle trajectory $[93,94]$, (3) mass and heat balance, and (4) ice accretion. Most of the current focus of numerical research is on the mass and heat balance calculations [95]. Many efforts are made in the extension of the Messinger model (Section 2.1) to deal with the mass flow rate of ice particles [96] as well as the erosion of accreted ice caused by ice particle impingement [97].

The most significant difference between the Messinger model and ice crystal icing simulations is the consideration of the ice particles. While there have been several discussions on the development of models for ice crystal icing [89,98], Trontin and Viledieu [96] provided a straightforward schematic of the water mass rate in a control volume on the ice accretion site, as shown in Figure 7. The following equations are derived based on the conservation of mass rate given in Figure 7:

$$
\begin{gathered}
\dot{m}_{a c c}^{S}+\dot{m}_{M e s s}^{L}=\dot{m}_{r b i}+\dot{m}_{d e p}-\dot{m}_{e v s}-\dot{m}_{e r} \\
\dot{m}_{M e s s}^{L}=\dot{m}_{a c c}^{L}+\dot{m}_{r b o}
\end{gathered}
$$

where $\dot{m}_{a c c}^{S}$ is the mass rate of ice accretion, $\dot{m}_{\text {Mess }}^{L}$ is the liquid water mass flow rate that remains in the liquid state, $\dot{m}_{r b i}$ is the incoming runback liquid water mass flow rate, $\dot{m}_{d e p}$ is the total water mass flow rate deposited into the control volume, $\dot{m}_{\text {evs }}$ is the mass rate of evaporating and sublimating water, and $\dot{m}_{e r}$ is the mass rate of erosion. $\dot{m}_{\text {Mess }}^{L}$ is further divided into $\dot{m}_{a c c}^{L}$ and $\dot{m}_{r b o}$, which are the liquid mass rate that is trapped inside the porous ice layer and the outgoing runback water mass rate. The deposited water mass rate, $\dot{m}_{\text {dep }}$, can be expressed using $\dot{m}_{i m p}$ and $\varepsilon_{s}$, which are the impinging mass rate and the sticking 
efficiency, respectively. Here, the sticking efficiency is the ratio of the mass sticking to the clear/iced surface to the mass bouncing off to the air flow.

$$
\dot{m}_{d e p}=\varepsilon_{s} \dot{m}_{i m p}
$$

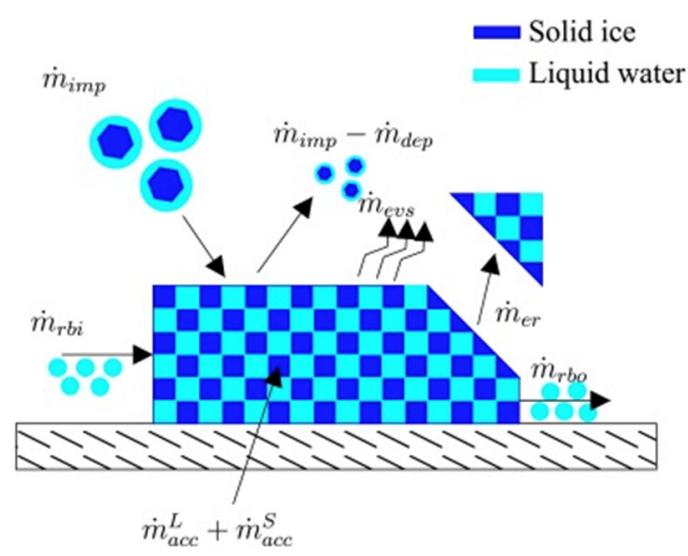

Figure 7. Schematic of parameters contributing to the mass conservation (obtained from [96]).

Note that the impinging mass rate, $\dot{m}_{i m p}$, can be used to describe the impinging water mass rate, $\dot{m}_{i m p}^{L}$, and the impinging ice crystal mass rate, $\dot{m}_{i m p}^{S}$, as follows:

$$
\begin{gathered}
\dot{m}_{i m p}^{L}=\eta_{m} \dot{m}_{i m p} \\
\dot{m}_{i m p}^{S}=\left(1-\eta_{m}\right) \dot{m}_{i m p}
\end{gathered}
$$

where $\eta_{m}$ is the melting ratio of the impinging ice crystals.

While the melting ratio, $\eta_{m}$, can be measured, the sticking efficiency, $\varepsilon_{s}$, the fraction of impinging mass that adheres to a surface [99], is left unknown. Trontin and Viledieu [96] developed an empirical model based on the experimental results from Currie et al. [100]. They measured the sticking efficiency at the stagnation point of a crowned cylinder over a small value range of the melting ratio at Mach 0.25 and 0.4.

Trontin and Viledieu argued that the sticking efficiency resulted from the competition between the ice accretion due to incoming water droplets or ice crystals and the erosion due to the ice crystals. Since the erosion rate is mostly determined by the tangential velocity of ice crystals, they assume that the sticking efficiency in the glaciated condition can be considered as a function of the melting ratio as follows:

$$
\varepsilon_{s}=F\left(\eta_{m}\right)
$$

They derived this function on the following assumptions:

1. When only ice crystals exist $\left(\eta_{m}=0\right)$, the sticking efficiency becomes 0 since all ice crystals bounce off the wall $(F(0)=0)$.

2. When only supercooled water droplets exist $\left(\eta_{m}=1\right)$, the sticking efficiency becomes 1 since all impinging droplets stick to the wall.

3. In the small $\eta_{m}$ region in Figure 8, the function can be considered linear such that $F\left(\eta_{m}\right)=K^{\#} \eta_{m}$ where $K^{\#}$ is an adjustable number.

4. The function is smooth and increases with the melting ratio. 


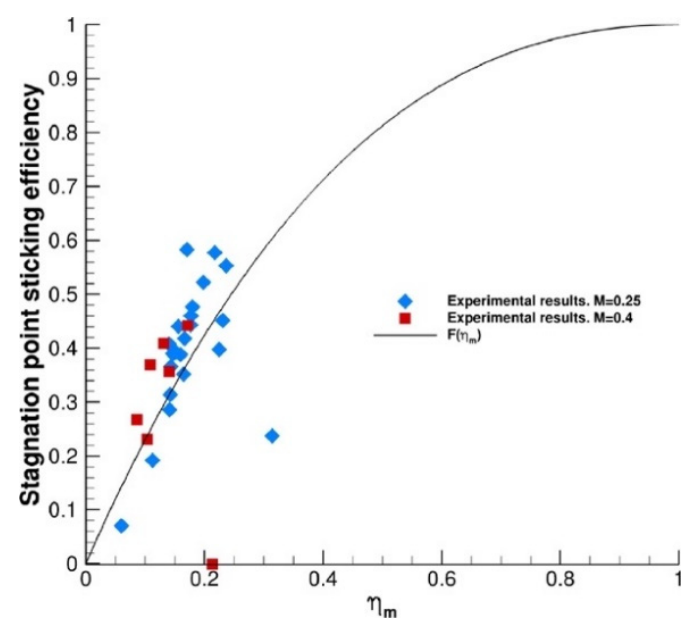

Figure 8. Relation between the melting ratio and sticking efficiency (obtained from [96]).

They expressed the function as polynomials.

$$
F\left(\eta_{m}\right)=\left(K^{\#}-2\right) \eta_{m}{ }^{3}+\left(2-K^{\#}\right) \eta_{m}{ }^{2}+K^{\#} \eta_{m}
$$

Based on Figure $8, K^{\#}$ was calibrated as 2.5 .

Baumert et al. [101] modified the sticking efficiency in the mixed-phase conditions. In this case, the sticking efficiency of the mixed ice crystal depends on the ratio of liquid to total water content at the wall required for the ice crystal to stick, $m_{\text {stick }}$.

$$
\varepsilon_{s}=F\left(m_{\text {stick }}\right)
$$

$m_{\text {stick }}$ is expressed as

$$
m_{\text {stick }}=K_{d} f_{1}
$$

where $K_{d}$ is an adjustable parameter and $f_{1}$ is the total liquid fraction at the wall given as

$$
f_{1}=\frac{\dot{m}_{a c c}^{L}+\dot{m}_{r b o}}{\dot{m}_{a c c}^{L}+\dot{m}_{r b o}+\dot{m}_{a c c}^{S}}=\frac{\dot{m}_{\text {Mess }}^{L}}{\dot{m}_{\text {Mess }}^{L}+\dot{m}_{a c c}^{S}}
$$

By introducing the same assumptions made in [8], the function $F\left(m_{\text {stick }}\right)$ is assumed to be

$$
F\left(m_{\text {stick }}\right)=\left(K^{\#}-2\right) m_{\text {stick }}{ }^{3}+\left(2-K^{\#}\right) m_{\text {stick }}{ }^{2}+K^{\#} m_{\text {stick }}
$$

Note that the variable of this function for the glaciated condition is the melting ratio $\eta_{m}=L W C /$ TWC while the variable for the glaciated condition is the ratio of liquid to total water content at the wall. The adjustable parameters $K_{d}$ and $K^{\#}$ were chosen to be 0.3 and 2.5 , respectively.

Since researchers' interest in ice crystal icing started growing recently, knowledge on fundamental physics is still limited, both in terms of the full-size engine scale and the ice crystal scale. As of now, it is clear that a detailed description of ice crystal impingement behavior such as breaking, eroding, and sticking on the clear/iced surface may improve the fidelity of a simulation.

\section{Mitigation Techniques}

Along with understanding the fundamental icing physics, the development of icing mitigation techniques is vital to improving airworthiness in icing conditions. Since such activities began during World War II, several methods were introduced to mitigate the adverse effects of icing [4]. Those mitigation techniques can be classified as either active or passive mitigations. The active mitigation technique uses energy from an external system, 
while the passive mitigation technique utilizes the physical or chemical properties to combat icing [102]. In addition, there are two distinct concepts in icing mitigation techniques: antiicing and deicing. The anti-icing techniques ultimately prevent ice accretion, while the deicing techniques remove ice deposits accreted on the surface [103].

\subsection{Active Mitigation}

(1) Thermal Method

The thermal method refers to the mitigation techniques that use heat to increase the surface temperature to prevent icing (anti-icing) or melt the accreted ice (deicing). The heat can be provided from either exhaust gas from the engine (hot air) or an electrical heater embedded underneath the surface of the wing. The thermal method is the most widely used method of icing mitigation for wings [104]. While it ensures a safe flight under icing conditions, energy consumption has been a major topic of discussion. For the bleed air system, $2.5 \sim 5 \%$ of the core engine mass flow is required according to $[105,106]$. This energy extraction contributes to the increase in fuel consumption. Therefore, lower energy consumption is desirable. The electrothermal method is used for fixed wings and propellers and helicopter rotors where the bleed air system cannot be installed. However, since electrical power is provided by onboard generators and thus limited during the flight [107], a reduction in energy consumption is necessary.

To optimize these devices, the required energy to mitigate icing (anti-/deicing) under given icing conditions must be understood. Some approaches to categorizing the parameters affect the energy requirement for icing mitigation $[108,109]$. However, they are similar to the following:

- Meteorological parameters.

- Ambient temperature, air pressure, air speed, mean volumetric diameter of water droplet (MVD), liquid water content (LWC), etc.

- Structural parameters of the wing.

- Types of materials, wing skin thickness, leading-edge geometry, etc.

- Anti-/deicing system parameters.

- Piccolo tube size, cross-section shape, number of piccolo holes, hole diameter, etc. (hot air).

- Heater placement, power density, etc. (electrothermal).

Arguments regarding the optimization of the thermal mitigation technique have been developed to focus on the surface temperature distribution of the mitigation site. The surface temperature can be investigated experimentally [110] with icing wind tunnel tests or numerically by utilizing the aircraft icing simulation discussed in Section 2.1. Due to the relatively high cost and limitations in experimental conditions, which cannot cover the icing conditions defined in [5], numerical investigations are often selected [104].

Since aircraft icing simulations have been capable of considering the heat provided from the electrothermal mitigation [69], the piccolo tube parameters such as hole spacing and Reynolds number of impinging hot air extracted from the engine are added to deal with the hot-air icing mitigation system in the form of correlations [111,112]. Along with the improvement of aircraft icing simulations, a parameter sensitivity analysis has been conducted. Pourbagian and Habashi conducted a parametric study for the energy requirements [108]. They reported both individual and multiple effects of parameters such as MVD, LWC, surface temperature, ambient temperature, airspeed, and angle of attack on the energy requirement. Zhou et al. investigated the effect of the meteorological conditions on the surface temperature and the runback ice [113]. They concluded that the LWC and the Mach number had more influence than the air temperature. Papadakis et al. investigated the effect of piccolo parameters, including its geometry, hot-air temperature, and hot-air mass flow rate, on the hot-air system performance. They confirmed that the surface temperature was sensitive to the geometric relation between the piccolo tube, the leading edge of the wing, and the hole pattern on the piccolo tube [114]. They also reported the effect of the hot-air mass flow and temperature on the surface temperature [115]. Zhang 
et al. conducted the sensitivity analysis on the hot-air system performance [116]. They concluded that the hole diameter on the piccolo tube was one of the critical structural parameters. In addition to optimizing thermal icing mitigation for the wing, a similar trend can be seen to optimize the mitigation of icing on the engine inlet guide vane [117-120].

(2) Mechanical Method

The mechanical methods refer to the mitigation techniques that apply a mechanical force onto the accreted ice to break and remove ice from the surface. Since it allows a certain amount of ice accretion, this icing mitigation technique is considered deicing. One of the representative mechanical mitigation systems is a pneumatic boot (Figure 9). A sheet of rubber is attached to the surface of the leading edge of the wing, and it breaks the accreted ice when inflated by pressurized air. Compared to the thermal method, this system has advantages in small weight and low cost [121]. Therefore, aircraft such as helicopters and propeller airplanes adopt pneumatic boots due to the limited weight tolerance and energy source.

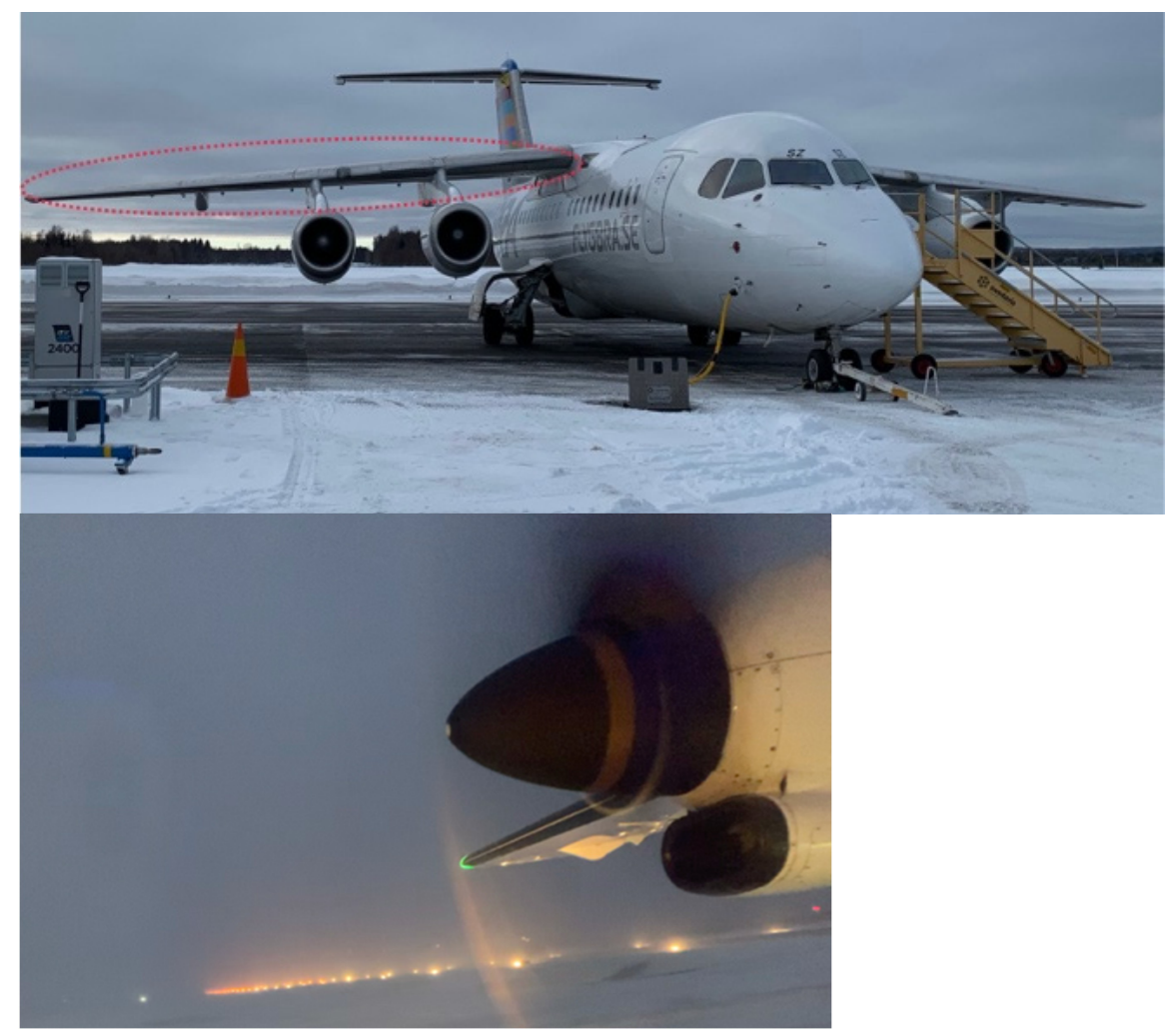

Figure 9. Examples of pneumatic deicing boot.

Since the pneumatic boot deicer can remove the accreted ice only after the thickness becomes larger than a threshold value, an improvement in its efficiency is required so that the ice can be removed at as thin a threshold as possible [122]. As more efficient deicing systems were demanded, several electromechanical methods were proposed [122]. The electroexpulsive separation system (EESS) consists of pairs of two layers of boots (Figure 10). When current flows in opposite directions between the layers, the magnetic fields produce force such that the layers separate from each other, resulting in the deformation of the outer layer. Accreted ice breaks up due to this deformation. The electromagnetic impulse deicer (EIDI) uses coils embedded under the metal skin and a high-voltage capacitor (Figure 11) [123]. When the capacitor is discharged, the coils create a rapidly forming and collapsing electromagnetic field. The magnetic field induces the eddy currents in the metal skin, causing a repulsive force that detaches the ice [124]. 


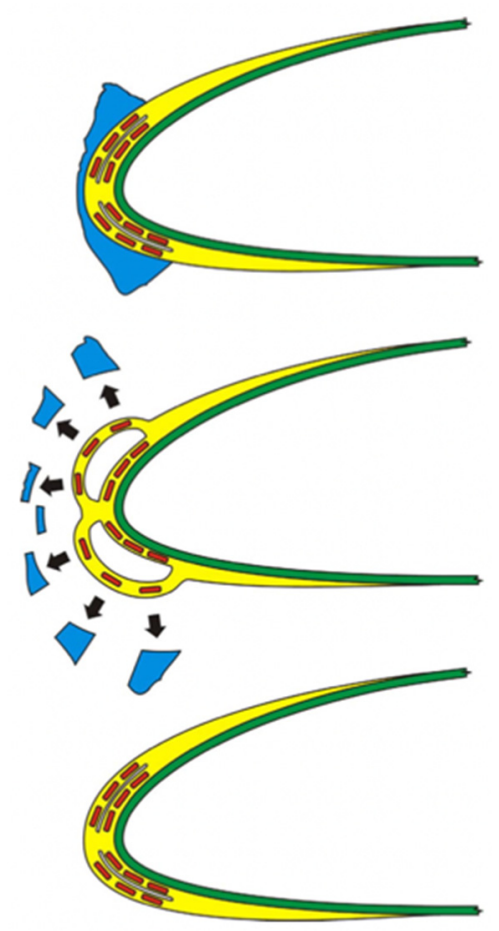

Figure 10. Deicing mechanism of EESS (Reproduced with permission from Goraj, Z. [125]).

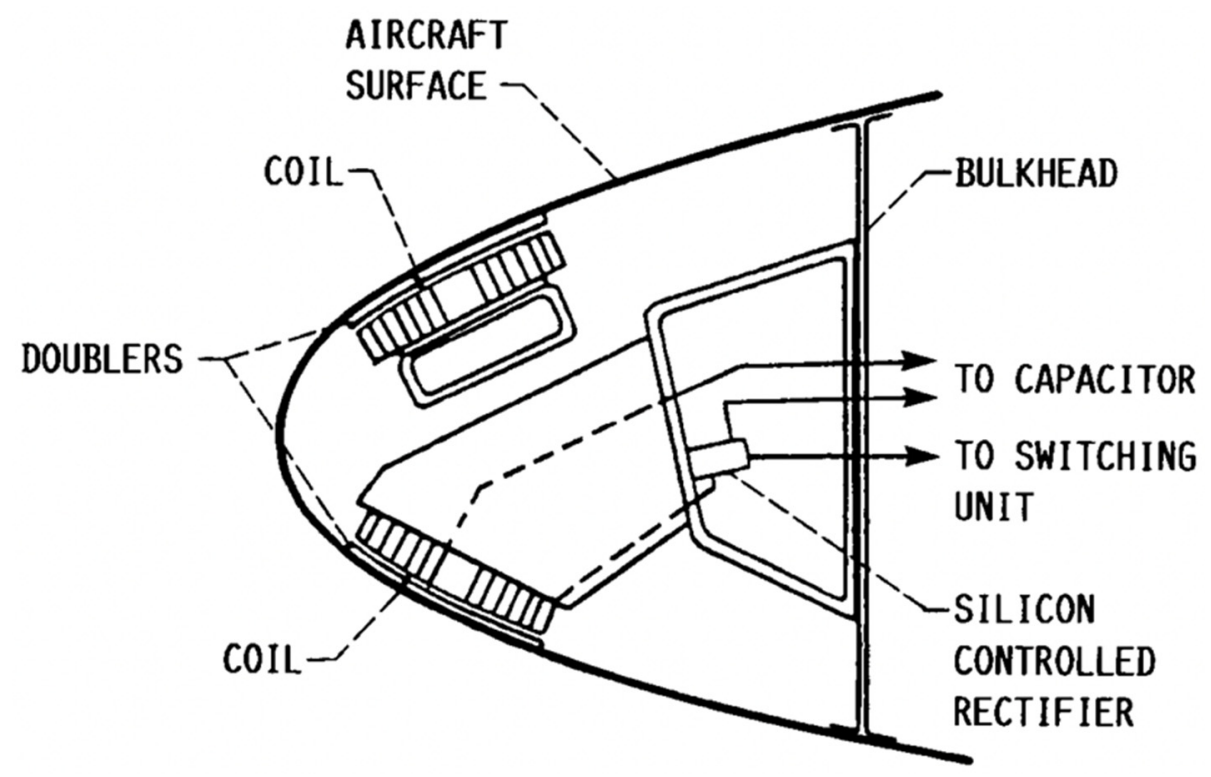

Figure 11. Schematic of EIDI (obtained from [122]).

\section{(3) Chemical Method}

A mitigation technique using a chemical method has been studied. It utilizes a substance's chemical properties to either lower freezing temperature or lower ice adhesion to prevent icing. The former approach can be seen on the ground before the flight [126]. Depending on the mixture of chemical fluids, this approach works as both deicing and anti-icing. The freezing depressant for deicing consists of ethylene or propylene glycol and hot water and is used to remove the accreted ice [127]. On the other hand, the fluid for anti-icing is similar to that for deicing, and it is known that polymers increase the viscosity [127].

While the chemical method has been used for ground de-/anti-icing, the environmental influence of those freezing depressants has been an area of concern $[128,129]$. When 
a glycol product is released to the soil or river near airports, the biochemical oxygen demand (BOD) increases. Here, BOD is the amount of oxygen consumed by bacteria or microorganisms to decompose organic materials and is used as one indicator for the quality of water. Several studies on the environmental effect of freezing depressants have been conducted, and it was revealed that additives in the freezing depressant rather than glycol contributed to the increase in BOD $[130,131]$, especially benzotriazole, which inhibits metal corrosion [132]. Since then, investigations of the influence of freezing depressants on the environment have focused on the presence of benzotriazole [133-136].

\subsection{Passive Mitigation}

\section{(1) Physicochemical Method}

The next set of techniques used to mitigate ice adhesion uses a physicochemical approach. It reduces ice adhesion on an aircraft surface by changing the surface properties so that ice can be easily removed from the surface [137]. This surface modification has been mainly done through surface coatings, and those coatings are often called icephobic coatings. Although the development of icephobic coating has been conducted over decades [138], they have not yet been adopted by commercial aircraft. The focus of the research is the low ice adhesion as well as the durability of the icephobic surface [139].

Hydrophobic coatings have long been investigated for their icephobicity [140]. On hydrophobic coatings, ice formation is delayed since water droplets are repelled before crystallization [141]. In addition, the smaller contact area between the water droplet and surface results in a low ice adhesion [140]. Developments of hydrophobic coatings as icephobic coatings are still ongoing [142-149]. Recently, the low ice adhesion of $9 \mathrm{kPa}$ was reported on a micro-nanostructured surface in [150]. Since the 2010s, the slippery lubricantinfused porous surface (SLIPS) has gained attention as an icephobic coating [151,152]. This type of coating works as a lubricant between the ice and surface, resulting in the low ice adhesion between 15 and $25 \mathrm{kPa}$ reported in $[153,154]$ compared to the ice adhesion of $821.9 \mathrm{kPa}$ for bare aluminum [155]. However, the icephobicity of SLIPS had a short lifetime since the lubricant was depleted through evaporation or consumption [156]. In order to increase the durability, an icephobic surface with bioinspired solid organogel materials has been developed [157]. While the sacrificial alkane surface layer is depleted with the removed ice, the layer can be regenerated from the crosslinked poly-dimethylsiloxane (PDMS) swelled by the molten alkane. More details on icephobic coatings can be found in the summaries of current studies presented by Shen et al. [158] and Zhuo et al. [159].

\subsection{Hybrid Mitigation}

Icephobic coatings are an ideal mitigation technique in energy consumption since they do not require any energy source. While various icephobic coatings have been developed, none of the coatings has been proven applicable for aerospace applications [160]. Instead, the hybrid mitigation technique in which the coatings are used to support an active mitigation technique has been considered. One such example is the mitigation technique combining electrical heating and an icephobic coating proposed by Morita et al. [161]. To lower the power consumption of the electrical heater, the heating temperature should be lower and/or the heating area should be minimized. However, in that case, ice accretion occurs when impinged water is moved to the unheated region by the local airflow. The icephobic coating based on a hydrophobic surface is applied right after the heating area, which prompts the detachment of the water from the surface of the airfoil before freezing. They reported that the combination of the thermal method and the icephobic coating only used $30-70 \%$ of the power consumption of the thermal method itself. Another hybrid mitigation was proposed in [162] which combined the icephobic coating and electromechanical mitigation techniques such as EESS and EIDI. Although the concept has been proposed, further investigation is required to evaluate its effectiveness due to the low maturity stage of the research [160]. 


\section{Conclusions}

The icing on an aircraft has been a major threat to flight safety. Researchers have focused on understanding the underlying physics of icing and developing better icing mitigation techniques in energy consumption. This review article aimed to summarize such advancements in icing physics and icing mitigation. Research on the icing physics was reviewed in three parts: fixed wings, rotors, and engines. Researchers focused on microscale phenomena such as droplet splashing and surface roughness of the accreted ice for icing on a fixed wing. For icing on rotors, implementing three-dimensional effects such as the ice shedding into icing simulations has been the main focus of the research. Engine icing, also known as the ice crystal icing, was a relatively new area of the research compared to icing on fixed wings and rotors. Researchers worked to understand the fundamental mechanism of ice crystal icing and develop better simulation tools.

Five types of icing mitigation methods were reviewed as the current technology in aircraft icing. The thermal and mechanical methods as active mitigation techniques have already been used in flight operations. For the thermal method, there has been a significant push to achieve lower energy consumption. On the other hand, several new types of mitigation techniques using electrical power were proposed for the mechanical method. The chemical method as passive mitigation has been used to mitigate the icing on the aircraft on the ground. Since the freezing depressant may influence the environment, considerable research activities have been carried out to evaluate the environmental impacts of this ice mitigation technique. An additional method, the physiochemical method, was developed as a passive mitigation technique. Hydrophobic coatings have been developed as icephobic coatings, and recent interest has grown surrounding the slippery lubricant-infused porous surface (SLIPS). The hybrid mitigation technique was also introduced. It lowers the energy consumption of the thermal method by combining it with the icephobic coating.

As can be seen from this review of the current achievements in aircraft icing physics and techniques for the mitigation of aircraft icing, the focus of most research has been on (1) acquiring the knowledge on details of underlying icing physics and (2) improving the mitigation techniques in terms of energy consumption. However, the ice crystal icing knowledge seems immature due to its short history of research activity. Consequently, the primary mitigation of the ice crystal icing is to avoid the area where the ice crystal icing is likely to occur. More investigations are demanded, especially for the ice crystal icing, to achieve better airworthiness. For an ice mitigation technique, hybrid mitigation is introduced, combining an active and a passive technique. It demonstrated a reduction in energy consumption compared to that of the existing active mitigation. Based on the current review, the research on this mitigation technique may grow. New hybrid mitigations will be seen, and their research challenges need to be highlighted.

Author Contributions: Conceptualization, H.S.; writing-original draft preparation, M.Y., A.J. and H.S.; writing-review and editing, A.J. and H.S.; supervision, H.S. All authors have read and agreed to the published version of the manuscript.

Funding: This research received no external funding.

Institutional Review Board Statement: Not applicable.

Informed Consent Statement: Not applicable.

Acknowledgments: Authors thank Elsevier, Zdobyslaw Goraj, Jose Palacios and Edward Brouwers for their permissions to use their figures in this paper.

Conflicts of Interest: The authors declare no conflict of interest.

\section{References}

1. Perkins, P.J.; Rieke, W.J. Aircraft icing problems-After 50 years. In Proceedings of the 31st Aerospace Sciences Meeting and Exhibit, Reno, NV, USA, 11-14 January 1993.

2. Potapczuk, M.G. Aircraft Icing Research at NASA Glenn Research Center. J. Aerosp. Eng. 2013, 26, 260-276. [CrossRef]

3. Bragg, M.B.; Broeren, A.P.; Blumenthal, L.A. Iced-airfoil aerodynamics. Prog. Aerosp. Sci. 2005, 41, 323-362. [CrossRef] 
4. Thomas, S.K.; Cassoni, R.P.; MacArthur, C.D. Aircraft Anti-Icing and De-Icing Techniques and Modeling. J. Aircr. 1996, 33, 841-854. [CrossRef]

5. Federal Aviation Administration. Icing Design Envelopes (14 CFR Parts 25 and 29, Appendix C) Converted to a Distance-Based Format; Federal Aviation Administration: Washington, DC, USA, 2002.

6. National Transportation Safety Board. In-Flight Icing Encounter and Loss of Control Simmons Airlines, d.b.a. American Eagle Flight 4184 Avions de Transport Regional (ATR) Model 72-212, N401AM, Roselawn, Indiana; Aircraft Accident Report; National Transportation Safety Board: Washington, DC, USA, 1996; Volume 1.

7. Mason, J.G.; Strapp, J.W.; Chow, P. The Ice Particle Threat to Engines in Flight. In Proceedings of the 44th AIAA Aerospace Sciences Meeting and Exhibit, Reno, NV, USA, 9-12 January 2006. [CrossRef]

8. Oliver, M.J. Validation Ice Crystal Icing Engine Test in the Propulsion Systems Laboratory at NASA Glenn Research Center. In Proceedings of the 6th AIAA Atmospheric and Space Environments Conference, Atlanta, GA, USA, 16-20 June 2014.

9. Federal Aviation Administration. 14 CFR Appendix D to Part 33-Mixed Phase and Ice Crystal Icing Envelope (Deep Convective Clouds); Amdt. 33-34, 79 FR 65538, 4 November 2014; Federal Aviation Administration: Washington, DC, USA, 2014.

10. European Aviation Safety Agency. Certification Specifications and Acceptable Means of Compliance for Large Aeroplanes CS-25; European Aviation Safety Agency: Cologne, Germany, 2016.

11. Gent, R.W.; Dart, N.P.; Cansdale, J.T. Aircraft Icing. Philos. Trans. R. Soc. Lond. Ser. A Math. Phys. Eng. Sci. 2000, $358,2873-2911$. [CrossRef]

12. Cebeci, T.; Kafyeke, F. Aircraft Icing. Annu. Rev. Fluid Mech. 2003, 35, 11-21. [CrossRef]

13. Lynch, F.T.; Khodadoust, A. Effects of ice accretion on aircraft aerodynamics. Prog. Aerosp. Sci. 2001, 37, 669-767. [CrossRef]

14. Cao, Y.; Tan, W.; Wu, Z. Aircraft icing: An ongoing threat to aviation safety. Aerosp. Sci. Technol. 2018, 75, 353-385. [CrossRef]

15. Mason, J.; Chow, P.; Riley, J. Engine Ice Crystal Icing Technology Plan with Research Needs; Federal Aviation Administration: Washington, DC, USA, 2020.

16. Leary, W.M. We Freeze to Please: A History of NASA's Icing Research Tunnel and the Quest for Flight Safety; NASA: Washington, DC, USA, 2002.

17. Shaw, R.J.; Potapczuk, M.G.; Bidwell, C.S. Predictions of Airfoil Aerodynamic Performance Degradation Due to Icing. In Numerical and Physical Aspects of Aerodynamic Flows IV; Cebeci, T., Ed.; Springer: Berlin/Heidelberg, Germany, 1990.

18. Langmuir, I.; Blodgett, K.B. A Mathematical Investigation of Water Droplet Trajectories; Army Airforce TR No. 5418; US Army Airforces: Washington, DC, USA, 1946.

19. Messinger, B.L. Equilibrium Temperature of an Unheated Icing Surface as a Function of Air Speed. J. Aeronaut. Sci. 1953, 20, 29-41. [CrossRef]

20. Cao, Y.; Ma, C.; Zhang, Q.; Sheridan, J. Numerical simulation of ice accretions on an aircraft wing. Aerosp. Sci. Technol. 2012, 23, 296-304. [CrossRef]

21. Shin, J.; Bond, T.H. Results of an icing test on a NACA 0012 airfoil in the NACA Lewis icing research tunnel. In Proceedings of the 30th Aerospace Sciences Meeting and Exhibit, Reno, NV, USA, 6-9 January 1992.

22. Arizmendi, B.; Morelli, M.; Parma, G.; Zocca, M.; Quaranta, G.; Guardone, A. In-flight Icing: Modeling, Prediction, and Uncertainty. In Optimization under Uncertainty with Applications to Aerospace Engineering; Vasile, M., Ed.; Springer: Cham, Switzerland, 2021; pp. 455-506.

23. Bourgault, Y.; Habashi, W.G.; Dompierre, J.; Baruzzi, G.S. A Finite Element Method Study of Eulerian Droplets Impingement Models. Int. J. Numer. Methods Fluids 1999, 29, 429-449. [CrossRef]

24. Tan, J.; Papadakis, M.; Sampath, M.K. Computational Study of Large Droplet Breakup in the Vicinity of an Airfoil; Federal Aviation Administration: Washington, DC, USA, 2005.

25. Vargas, M.; Feo, A. Experimental Observations on the Deformation and Breakup of Water Droplet near the Leading Edge of an Airfoil; NASA/TM-2011-216946; NASA: Washington, DC, USA, 2010.

26. Hsiang, L.P.; Faeth, G.M. Secondary Drop Breakup in the Deformation Regime. In Proceedings of the 30th Aerospace Sciences Meeting and Exhibit, Reno, NV, USA, 6-9 January 1993.

27. Pilch, M.; Erdman, C.A. Use of Breakup Time Data and Velocity History Data to Predict the Maximum Size of Stable Fragments for Acceleration-Induced Breakup of a Liquid Drop. Int. J. Multiph. Flow 1987, 13, 741-757. [CrossRef]

28. Honsek, R.; Habashi, W.G. Eulerian modeling of in-flight icing due to supercooled large droplets. J. Aircr. 2008, 45, 1290-1296. [CrossRef]

29. ANSYS, Inc. ANSYS FENSAP-ICE User Manual; ANSYS, Inc.: Canonsburg, PA, USA, 2020.

30. Rutkowski, A.; Potapczuk, M. Numerical Study of Droplet Splashing and Re-impingement. In Proceedings of the 41st Aerospace Science Meeting and Exhibit, Reno, NV, USA, 6-9 January 2003.

31. Wright, W.B.; Potapczuk, M.G. Semi-empirical modeling of SLD physics. In Proceedings of the 42nd AIAA Aerospace Science Meeting and Exhibit, Reno, NV, USA, 5-8 January 2004.

32. Yarin, A.L. Drop Impact Dynamics: Splashing, Spreading, Receding, Bouncing. Annu. Rev. Fluid Mech. 2006, $38,159-192$. [CrossRef]

33. Bai, C.; Gosman, A. Development of Methodology for Spray Impingement Simulation. SAE Trans. 1995, 104, 550-568.

34. Wang, M.; Watkins, A.P. Numerical Modeling of Diesel Spray Wall Impaction Phenomena. Int. J. Heat Fluid Flow 1993, 14, 301-312. [CrossRef] 
35. Stanton, D.; Rutland, C. Modeling Fuel Film Formation and Wall Interaction in Diesel Engines. SAE Trans. 1996, 105, 808-824.

36. Hirt, C.W.; Nichols, B.D. Volume of fluid (VOF) method for the dynamics of free boundaries. J. Comput. Phys. 1981, 39, 201-225. [CrossRef]

37. Trapaga, G.; Szekely, J. Mathematical modeling of the isothermal impingement of liquid droplets in spraying processes. Metall. Mater. Trans. B 1991, 22, 901-914. [CrossRef]

38. Lian, Y. Numerical simulation of supercooled large droplets using the moment of fluid method. In Proceedings of the 53rd Aerospace Science Meeting, National Harbor, MD, USA, 13-17 January 2014.

39. Cao, Y.; Xin, M. Numerical Simulation of Supercooled Large Droplet Icing Phenomenon: A Review. Arch. Comput. Methods Eng. 2020, 27, 1231-1265. [CrossRef]

40. Mundo, C.; Sommerfeld, M.; Tropea, C. Droplet-wall collisions: Experimental studies of the deformation and breakup process. Int. J. Multiph. Flow 1995, 21, 151-173. [CrossRef]

41. Cossali, G.E.; Coghe, A.; Marengo, M. The impact of a single drop on a wetted solid surface. Exp. Fluids 1997, $22,463-472$. [CrossRef]

42. Trujillo, L. Modeling and Experiment of Impingement and atomization of a liquid spray on a wall. J. Engine Res. 2000, 1, 87-105. [CrossRef]

43. Wright, W.B. Further Refinement of the LEWICE SLD Model. In Proceedings of the 44th AIAA Aerospace Sciences Meeting and Exhibit, Reno, NV, USA, 9-12 January 2006.

44. Honsek, R. Development of a Three Dimensional Eulerian Model of Droplet-Wall Interaction Mechanisms. Master's Thesis, McGill University, Montreal, QC, Canada, June 2005.

45. Papadakis, M.; Rachman, A.; Wong, S.C.; Yeong, H.W.; Hung, K.; Bidwell, C. Water Impingement Experiments on a NACA 23012 Airfoil with Simulated Glaze Ice Shapes. In Proceedings of the 42nd AIAA Aerospace Science Meeting and Exhibit, Reno, NV, USA, 5-8 January 2004.

46. Myers, T.G. An extension to the Messinger Model for Aircraft Icing. AIAA J. 2001, 39, 211-218. [CrossRef]

47. Olsen, W.; Shaw, R.; Newton, J. Ice shapes and the resulting drag increase for a NACA 0012 airfoil. In Proceedings of the 22nd Aerospace Science Meeting, Reno, NV, USA, 9-12 January 1984.

48. Shin, J. Characteristics of surface roughness associated with leading edge ice accretion. J. Aircr. 1996, 33, 316-321. [CrossRef]

49. Anderson, D.N.; Shin, J. Characterization of ice roughness from simulated icing encounters. In Proceedings of the 35th Aerospace Sciences Meeting and Exhibit, Reno, NV, USA, 6-9 January 1997.

50. Anderson, D.; Hentschel, D.; Ruff, G. Measurement and Correlation of Ice Accretion Roughness. In Proceedings of the 36th AIAA Aerospace Sciences Meeting and Exhibit, Reno, NV, USA, 12-15 January 1998.

51. Han, Y.; Palacios, J. Surface Roughness and Heat Transfer Improved Predictions for Aircraft Ice-Accretion Modeling. AIAA J. 2017, 55, 1318-1331. [CrossRef]

52. Ignatowicz, K.; Morency, F.; Beaugendre, H. Numerical simulation of ice accretion using Messinger-based approach: Effects of surface roughness. In Proceedings of the CASI Aero 2019-Canadian Aeronautics and Space Institute's AERO 2019 Conference, Laval, QC, Canada, 14-16 May 2019.

53. Aupoix, B. Improved heat transfer predictions on rough surfaces. Int. J. Heat Fluid Flow 2015, 56, 160-171. [CrossRef]

54. Han, Y.; Palacios, J. Surface Roughness and Heat Transfer Prediction for Development of an Improved Aircraft Ice Accretion Modeling Tool. In Proceedings of the 8th AIAA Atmospheric and Space Environments Conference, AIAA AVIATION Forum, Washington, DC, USA, 13-17 January 2016.

55. McClain, S.; Vargas, M.; Tsao, J.; Broeren, A.; Lee, S. Ice Accretion Roughness Measurements and Modeling. In Proceedings of the 7th European Conference for Aeronautics and Space Sciences, European Conference for AeroSpace Sciences, Milan, Italy, 3-7 July 2017.

56. Lee, S.; Broeren, A.; Addy, H.; Sills, R.; Pifer, E. Development of 3D Ice Accretion Measurement Method; NASA TM-2012-217702; NASA: Washington, DC, USA, 2012.

57. McClain, S.; Tino, T.; Kreeger, R. Ice Shape Characterization Using Self-Organizing Maps. J. Aircr. 2011, 48, 724-730. [CrossRef]

58. McClain, S.T.; Kreeger, R.E. Assessment of Ice Shape Roughness Using a Self-Organizing Map Approach. In Proceedings of the 5th AIAA Atmospheric and Space Environments Conference, San Diego, CA, USA, 24-27 June 2013.

59. McClain, S.T.; Vargas, M.; Tsao, J.C. Ice Roughness and Thickness Evolution on a Swept NACA0012 Airfoil. In Proceedings of the 9th AIAA Atmospheric and Space Environments Conference, Denver, CO, USA, 5-9 June 2017.

60. Wang, Z.; Zhao, N.; Zhu, C. Numerical simulation for three-dimensional rotor icing in forward flight. Adv. Mech. Eng. 2018, 10, 1-12. [CrossRef]

61. Bragg, M.B. Effect of Geometry on Airfoil Icing Characteristics. J. Aircr. 1984, 21, 505-511. [CrossRef]

62. Peterson, A.A.; Dadone, L.U. Helicopter Icing Review; FAA Contract DOT-FA78WA-4258; US Department of Transportation: Atlantic, NJ, USA, 1980.

63. Cao, Y.; Chen, K. Helicopter icing. Aeronaut. J. 2016, 114, 83-90. [CrossRef]

64. Perkins, P.J. Aircraft Icing; NASA Conference Publication 2086; NASA: Washington, DC, USA, 1978.

65. Flemming, R.J.; Britton, R.K.; Bond, T.H. Role of Wind Tunnels and Computer Codes in the Certification and Qualification of Rotorcraft for Flight in Forecast Icing; NASA TM-106747; NASA: Washington, DC, USA, 1994. 
66. Bell, J. Icing at the McKinley Climatic Laboratory. In Proceedings of the 41st Aerospace Sciences Meeting and Exhibit, Reno, NV, USA, 6-9 January 2003.

67. Palacios, J.L.; Han, J.; Brouwers, E.W.; Smith, E.C. Icing Environment Rotor Test Stand Liquid Water Content Measurement Procedures and Ice Shape Correlation. J. Am. Helicopter Soc. 2012, 57, 29-40. [CrossRef]

68. Palacios, J.L.; Brouwers, E.W.; Han, Y.; Smith, E.C. Adverse Environment Rotor Test Stand Calibration Procedures and Ice Shape Correlation. In Proceedings of the American Helicopter Society 66th Annual Forum, Phoenix, AZ, USA, 11-13 May 2010.

69. Wright, W.B. User's Manual for LEWICE Version 3.2; CR-2008-214255; NASA: Cleveland, OH, USA, 2008.

70. Beaugendre, H.; Morency, F.; Habashi, W.G. FENSAP-ICE's Three-Dimensional In-Flight Ice Accretion Module: ICE3D. J. Aircr. 2003, 40, 239-247. [CrossRef]

71. Hedde, T.; Guffond, D. ONERA Three-Dimensional Icing Model. AIAA J. 1995, 33, 1038-1045. [CrossRef]

72. Narducci, R.; Kreeger, R. Analysis of a Hovering Rotor in Icing Conditions; NASA TM-217126; NASA: Washington, DC, USA, 2012.

73. Lee, J.D.; Harding, R.; Palko, R.L. Documentation of Ice Shapes on the Main Rotor of a UH-1H Helicopter in Hover; NASA CR-168332; Lewis Research Center: Cleveland, OH, USA, 1983.

74. Busch, G.; Bragg, M. Computational Prediction of Propeller Performance in Icing Condition. In Proceedings of the AIAA Atmospheric and Space Environments Conference, Toronto, ON, Canada, 2-5 August 2010.

75. Brouwers, E.; Palacios, J.; Smith, E.; Peterson, A. The Experimental Investigation of a Rotor Hover Icing model with Shedding. In Proceedings of the American Helicopter Society 66th Annual Forum, Phoenix, AZ, USA, 11-13 May 2010.

76. Zhang, S.; El Kerdi, O.; Khurram, R.A.; Habashi, W.G. FEM Analysis of In-flight Ice Break-up. Finite Elem. Anal. Des. 2012, 57, 55-66. [CrossRef]

77. Zhang, S.; Khurram, R.A.; Fouladi, H.; Habashi, W.G. Computational Modeling of Ice Cracking and Break-up from Helicopter Blades. In Proceedings of the 4th AIAA Atmospheric and Space Environments Conference, New Orleans, LA, USA, 25-28 June 2012.

78. Zhao, G.; Zhao, Q.; Chen, X. New 3-D ice accretion method of hovering rotor including effects of centrifugal force. Aerosp. Sci. Technol. 2016, 48, 122-130. [CrossRef]

79. Wang, Z.; Zhu, C. Study of the Effect of Centrifugal Force on Rotor Blade Icing Process. Int. J. Aerosp. Eng. 2017, $2017,8695170$. [CrossRef]

80. Kelly, D.; Habashi, W.G.; Fossati, M. Ice Accretion Effects on Helicopter Rotor Performance, via Multibody and CFD Approached. J. Aircr. 2018, 55, 1165-1176. [CrossRef]

81. Bucknell, A.; McGilvray, M.; Gillespie, D.R.H.; Jones, G.; Reed, A.; Collier, B. Experimental Studies of Ice Crystal Accretion on Axisymmetric Bodies at Aeroengine Conditions. J. Propuls. Power 2020, 36, 836-850. [CrossRef]

82. Struk, P.; Currie, T.; Wright, W.B.; Knezevici, D.; Fuleki, D.; Broeren, A.; Vargas, M.; Tsao, J.C. Fundamental Ice Crystal Accretion Physics Studies; NASA TM-2012-217429; NASA: Washington, DC, USA, 2012.

83. Currie, T.; Struk, P.; Tsao, J.C.; Fuleki, D.; Knezevici, D. Fundamental Study of Mixed-Phase Icing with Application to Ice Crystal Accretion in Aircraft Jet Engines. In Proceedings of the 4th AIAA Atmospheric and Space Environments Conference, New Orleans, LA, USA, 25-28 June 2012.

84. Hauk, T. Investigation of the Impact and Melting Process of Ice Particles. Ph.D. Thesis, Technischen Universitat Darmstadt, Darmstadt, Germany, 26 January 2016.

85. Van Zante, J.F.; Bencic, T.J.; Ratvasky, T.P. Update on the NASA Glenn Propulsion Systems Lab Ice Crystal Cloud Characterization (2015). In Proceedings of the 8th AIAA Atmospheric and Space Environments Conference, Washington, DC, USA, 13-17 June 2016.

86. Davison, C.R.; Rutke, T.; Strapp, J.W.; Ratvasky, T.P.; Emery, E.F. Naturally Aspirating Isokinetic Total Water Content Probe: Pre-flight Wind Tunnel Testing and Design Modifications. In Proceedings of the 4th AIAA Atmospheric and Space Environments Conference, New Orleans, LA, USA, 25-28 June 2012.

87. Davison, C.; Strapp, J.W.; Lilie, L.E.; Ratvasky, T.P.; Dumont, C. Isokinetic TWC Evaporator Probe: Calculations and Systemic Error Analysis. In Proceedings of the 8th AIAA Atmospheric and Space Environments Conference, Washington, DC, USA, 13-17 June 2016.

88. Lang, B.; Breitfuss, W.; Schweighart, S.; Breitegger, P.; Pervier, H.; Tramposch, A.; Klug, A.; Hassler, W.; Bergmann, A. Photoacoustic hygrometer for icing wind tunnel water content measurement: Design, analysis, and intercomparison. Atmos. Meas. Tech. 2021, 14, 2477-2500. [CrossRef]

89. Wright, W.B.; Jorgenson, P.C.E.; Veres, J.P. Mixed Phase Modeling in GlennICE with Application to Engine Icing. In Proceedings of the AIAA Atmospheric and Space Environments Conference, Toronto, ON, Canada, 2-5 August 2010.

90. Trontin, P.; Kontogiannis, A.; Blanchard, G.; Villedieu, P. Description and assessment of the new ONERA2D icing suite IGLOO2D. In Proceedings of the 9th AIAA Atmospheric and Space Environments Conference, AIAA AVIATION Forum, Denver, CO, USA, 5-9 June 2017.

91. Nilamdeen, S.; Habashi, W.; Aube, M.; Baruzzi, G. FENSAP-ICE: Modeling of Water Droplets and Ice Crystals. In Proceedings of the 1st AIAA Atmospheric and Space Environments Conference, San Antonio, TX, USA, 22-25 June 2009.

92. Bucknell, A.; McGilvray, M.; Gillespie, D.; Yang, X.; Jones, G.; Collier, B. ICICLE: A Model for Glaciated \& Mixed Phase Icing for Application to Aircraft Engines. SAE Tech. Paper 2019. [CrossRef] 
93. Ganser, G.H. A rational approach to drag prediction of spherical and nonspherical particles. Power Technol. 1993, 77, 143-152. [CrossRef]

94. Norde, E.; Van der Weide, E.; Hoeijmakers, H. Eulerian Method for Ice Crystal Icing. AIAA J. 2018, 56, 222-234. [CrossRef]

95. Tsao, J.C.; Struk, P.M.; Oliver, M.J. Possible Mechanisms for Turbofan Engine Ice Crystal Icing at High Altitude. In Proceedings of the 6th AIAA Atmospheric and Space Environments Conference, Atlanta, GA, USA, 16-20 June 2014.

96. Trontin, P.; Villedieu, P. A comprehensive accretion model for glaciated icing conditions. Int. J. Multiph. Flow 2018, 108, 105-123. [CrossRef]

97. Charlton, V.; Senoner, J.M.; Trontin, P.; Villedieu, P. Semi-empirical Erosion Model with Particle Size and Liquid Water Content Effects for Ice Crystal Icing Simulations. In Proceedings of the AIAA Aviation 2020 Forum, Reno, NV, USA, 15-19 June 2020.

98. Villedieu, P.; Trontin, P.; Chauvin, R. Glaciated and mixed phase ice accretion modeling using ONERA 2D icing suite. In Proceedings of the 6th AIAA Atmospheric and Space Environments Conference, Atlanta, GA, USA, 16-20 June 2014.

99. Bartkus, T.P.; Tsao, J.C.; Struk, P.M. Analysis of Experimental Ice Accretion Data and Assessment of a Thermodynamic Model During Ice Crystal Icing. SAE Tech. Paper 2019. [CrossRef]

100. Currie, T.C.; Fuleki, D.M.; Mahallati, A. Experimental studies of mixed-phase sticking efficiency for ice crystal accretion in jet engines. In Proceedings of the 6th AIAA Atmospheric and Space Environments Conference, Atlanta, GA, USA, 16-20 June 2014.

101. Baumert, A.; Bansmer, S.; Trontin, P.; Villedieu, P. Experimental and numerical investigations on aircraft icing at mixed phase conditions. Int. J. Heat Mass Transf. 2018, 123, 957-978. [CrossRef]

102. Shohag, M.A.S.; Hammel, E.C.; Olawale, D.O.; Okoli, O.I. Damage mitigation techniques in wind turbine blades: A review. Wind Eng. 2017, 41, 185-210. [CrossRef]

103. Parent, O.; Ilinca, A. Anti-icing and de-icing techniques for wind turbines: Critical review. Cold Reg. Sci. Technol. 2011, 65, 88-96. [CrossRef]

104. Pellissier, M.P.C.; Habashi, W.G.; Peueyo, A. Optimization via FENSAP-ICE of Aircraft Hot-Air Anti-Icing Systems. J. Aircr. 2011, 48, 265-276. [CrossRef]

105. Yeoman, K.E. Efficiency of a Bleed Air Powered Inlet Icing Protective System. In Proceedings of the 32nd AIAA Aerospace Sciences Meeting and Exhibit, Reno, NV, USA, 10-13 January 1994.

106. Norris, R.M.; Rumford, K.J.; Youd, D.S. Anti-Icing Valve. U.S. Patent 4,831,819, 7 February 1987.

107. Ding, L.; Chang, S.; Leng, M. Transient characteristics of an electrothermal anti-icing process based on the improved messinger model. In Proceedings of the 2016 IEEE International Conference on Aircraft Utility Systems (AUS), Beijing, China, 10-12 October 2016.

108. Pourbagian, M.; Habashi, G.W. Parametric Analysis of Energy Requirements of In-Flight Ice Protection Systems. In Proceedings of the 20th Annual Conference of the CFD Society of Canada (CFD2012), Canmore, AB, Canada, 9-11 May 2012.

109. Wong, S.H.; Papadakis, M.; Zamora, A. Computational Investigation of a Bleed Air Ice Protection System. In Proceedings of the 1st AIAA Atmospheric and Space Environments Conference, San Antonio, TX, USA, 22-25 June 2009.

110. Planquart, P.; Vanden Borre, G.; Buchlin, J.M. Experimental and Numerical Optimization of a Wing Leading Edge Hot Air Anti-Icing System. In Proceedings of the 43rd AIAA Aerospace Sciences Meeting and Exhibit, Reno, NV, USA, 10-13 January 2005.

111. Wright, W.B. An Evaluation of Jet Impingement Heat Transfer Correlations for Piccolo Tube Application. In Proceedings of the 42nd AIAA Aerospace Sciences Meeting and Exhibit, Reno, NV, USA, 5-8 January 2004.

112. Brown, J.M.; Raghunathan, S.; Watterson, J.K.; Linton, A.J.; Riordon, D. Heat Transfer Correlation for Anti-Icing Systems. J. Aircr. 2002, 39, 65-70. [CrossRef]

113. Zhou, Y.; Lin, G.; Bu, X.; Mu, Z.; Pan, R.; Ge, Q.; Qiao, X. Temperature and Runback Ice Prediction Method for Three-Dimensional Hot Air Anti-Icing System. In IOP Conference Series: Materials Science and Enginering; IOP Publishing: Bristol, UK, 2017; Volume 187, p. 012017.

114. Papadakis, M.; Wong, S.H. Parametric investigation of a bleed air ice protection system. In Proceedings of the 44th AIAA Aerospace Sciences Meeting and Exhibit, Reno, NV, USA, 9-12 January 2006.

115. Papadakis, M.; Wong, S.H.; Yeong, H.W.; Wong, S.C.; Vu, G.T. Icing Tests of a Wing Model with a Hot-Air Ice Protection System. In Proceedings of the AIAA Atmospheric and Space Environments Conference, Toronto, ON, Canada, 2-5 August 2010.

116. Zhang, F.; Gao, Y.; Yao, H.; Wang, Y.; Luo, K. Structural Parameter Sensitivity Analysis of an Aircraft Anti-Icing Cavity Based on Thermal Efficiency. Int. J. Aerosp. Eng. 2019, 2019, 7851260. [CrossRef]

117. Guan, T.; Zhang, J.Z.; Shan, Y. Effect of offset-jets arrangement on leading edge hot-air heating effectiveness of engine inlet guide strut. Appl. Therm. Eng. 2018, 128, 357-372. [CrossRef]

118. Chen, N.; Hu, Y.; Ji, H.; Zhang, M. Hot-Air Anti-Icing Heat Transfer and Surface Temperature Modeling. AIAA J. 2021, 1-10. [CrossRef]

119. Li, L.; Liu, Y.; Tian, L.; Hu, H.; Hu, H.; Liu, X.; Hogate, I.; Kohli, A. An experimental study on a hot-air-based anti-/de-icing system for aero-engine inlet guide vanes. Appl. Therm. Eng. 2020, 167, 114778. [CrossRef]

120. Hui, M.; Dalin, Z. Experiment investigation of hot-air anti-icing structure of engine inlet vane. In Proceedings of the 2016 IEEE/CSAA International Conference on Aircraft Utility Systems (AUS), Beijing, China, 10-12 October 2016; pp. $284-289$.

121. Martin, C.; Putt, J. Advanced Pneumatic Impulse Ice Protection System (PIIP) for Aircraft. J. Aircr. 1992, 29, 714-716. [CrossRef] 
122. Reinmann, J.J.; Shaw, R.J.; Ranaudo, R.J. NASA's Program on Icing Research and Technology; NASA Technical Memorandum 101989; NASA: Cleveland, OH, USA, 1989.

123. Jiang, X.; Wang, Y. Studies on the Electro-Impulse De-Icing System of Aircraft. Aerospace 2019, 6, 67. [CrossRef]

124. Labeas, G.N.; Diamantakos, I.D.; Sunaric, M.M. Simulation of the electroimpulse de-icing process of Aircraft Wings. J. Aircr. 2006, 43, 1876-1885. [CrossRef]

125. Goraj, Z. An overview of the deicing and anti-icing technologies with prospects for the future. In Proceedings of the 24th International Congress of the Aeronautical Sciences, Yokohama, Japan, 29 August-3 September 2004.

126. Hill, E.G.; Zierten, T.A. Aerodynamic Effects of Aircraft Ground Deicing/Anti-Icing Fluids. J. Aircr. 1993, 30, 24-34. [CrossRef]

127. Corsi, S.R.; Mericas, D.; Bowman, G.T. Oxygen Demand of Aircraft and Airfield Pavement Deicers and Alternative Freezing Point Depressants. Water Air Soil Pollut. 2012, 223, 2447-2461. [CrossRef]

128. Kent, R.A.; Andersen, D.; Caux, P.Y.; Teed, S. Canadian water quality guidelines for glycols-An ecotoxicological review of glycols and associated aircraft anti-icing and deicing fluids. Environ. Toxicol. 1999, 14, 481-522. [CrossRef]

129. Jaesche, P.; Totsche, K.U.; Kögel-Knabner, I. Transport and anaerobic biodegradation of propylene glycol in gravel-rich soil materials. J. Contam. Hydrol. 2006, 85, 271-286. [CrossRef]

130. Hartwell, S.I.; Jordahl, D.M.; Evans, J.E.; May, E.B. Toxicity of Aircraft De-Icer and Anti-Icer Solutions to Aquatic Organisms. Environ. Toxicol. Chem. 1995, 14, 1375-1386. [CrossRef]

131. Pillard, D.A. Comparative Toxicity of Formulated Glycol Deicers and Pure Ethylene and Propylene Glycol to Ceriodaphnia Dubia and Pimephales Promelas. Environ. Toxicol. Chem. 1995, 14, 311-315. [CrossRef]

132. Cancilla, D.A.; Holtkamp, A.; Matassa, L.; Fang, X. Isolation and Characterization of Microtox-Active Components from Aircraft De-Icing/Anti-Icing Fluids. Environ. Toxicol. Chem. 1997, 16, 430-434. [CrossRef]

133. Cancilla, D.A.; Martinez, J.; van Aggelen, G.C. Detection of aircraft deicing/antiicing fluid additives in a perched water monitoring well at an international airport. Environ. Sci. Technol. 1998, 32, 3834-3835. [CrossRef]

134. Wolschke, H.; Xie, Z.; Möller, A.; Sturm, R.; Ebinghaus, R. Occurrence, distribution and fluxes of benzotriazoles along the German large river basins into the North Sea. Water Res. 2011, 45, 6259-6266. [CrossRef]

135. Giger, W.; Schaffner, C.; Kohler, H.P.E. Benzotriazole and tolyltriazole as aquatic contaminants. 1. Input and occurrence in rivers and lakes. Environ. Sci. Technol. 2006, 40, 7186-7192. [CrossRef]

136. Liu, Y.S.; Ying, G.G.; Shareef, A.; Kookana, R.S. Biodegradation of three selected benzotriazoles under aerobic and anaerobic conditions. Water Res. 2011, 45, 5005-5014. [CrossRef]

137. Lin, Y.; Chen, H.; Wang, G.; Liu, A. Recent Progress in Preparation and Anti-Icing Applications of Superhydrophobic Coatings. Coatings 2018, 8, 208. [CrossRef]

138. Laforte, C.; Carriere, J.C.; Laforte, J.L. How a Solid Coating Can Reduce the Adhesion of Ice on a Structure. In Proceedings of the 10th International Workshop on Atmospheric Icing of Structures IWAIS, Brno, Czech Republic, 17-20 June 2002.

139. Golovin, K.; Kobaku, S.; Lee, D.; Di Loreto, E.; Mabry, J.; Tuteja, A. Designing durable icephobic surfaces. Sci. Adv. 2016, 2, e1501496. [CrossRef] [PubMed]

140. Andersson, L.O.; Golander, G.C.; Persson, S. Ice Adhesion to Rubber Material. J. Adhes. Sci. Technol. 1994, 8, 117-132. [CrossRef]

141. Boinovich, L.B.; Emelyanenko, A.M. Anti-Icing Potential of Superhydrophobic Coatings. Mendeleev Commun. 2013, $23,3-10$. [CrossRef]

142. Farhadi, S.; Farzaneh, M.; Kulinich, S.A. Anti-icing performance of superhydrophobic surfaces. Appl. Surf. Sci. 2011, 257, 6264-6269. [CrossRef]

143. Saito, H.; Takai, K.; Yamauchi, G. Water- and ice-repellent coatings. Surf. Coat. Int. 1997, 80, 168-171. [CrossRef]

144. Kulinich, S.A.; Farzaneh, M. How Wetting Hysteresis Influences Ice Adhesion Strength on Superhydrophobic Surfaces. Langmuir 2009, 25, 8854-8856. [CrossRef] [PubMed]

145. Cao, L.; Jones, A.K.; Sikka, V.K.; Wu, J.; Gao, D. Anti-Icing Superhydrophobic Coatings. Langmuir 2009, 25, 12444-12448. [CrossRef] [PubMed]

146. Meuler, A.J.; Smith, J.D.; Varanasi, K.K.; Mabry, J.M.; McKinley, G.H.; Cohen, R.E. Relationships between Water Wettability and Ice Adhesion. ACS Appl. Mater. Interfaces 2010, 2, 3100-3110. [CrossRef]

147. Menini, R.; Ghalmi, Z.; Farzaneh, M. Highly resistant icephobic coatings on aluminum alloys. Cold Reg. Sci. Technol. 2011, 65, 65-69. [CrossRef]

148. Antonini, C.; Innocenti, M.; Horn, T.; Marengo, M.; Amirfazli, A. Understanding the effect of superhydrophobic coatings on energy reduction in anti-icing systems. Cold Reg. Sci. Technol. 2011, 67, 58-67. [CrossRef]

149. Piscitelli, F.; Chiariello, A.; Dabkowski, D.; Corraro, G.; Marra, F.; Di Palma, L. Superhydrophobic Coatings as Anti-Icing Systems for Small Aircraft. Aerospace 2020, 7, 2. [CrossRef]

150. Vazirinasab, E.; Maghsoudi, K.; Jafari, R.; Momen, G. A comparative study of the icephobic and self-cleaning properties of Teflon materials having different surface morphologies. J. Mater. Process. Technol. 2020, 276, 116415. [CrossRef]

151. Wong, T.S.; Kang, S.H.; Tang, S.K.Y.; Smythe, E.J.; Hatton, B.D.; Grinthal, A.; Aizenberg, J. Bioinspired self-repairing slippery surfaces with pressure-stable omniphobicity. Nature 2011, 477, 443-447. [CrossRef]

152. Ma, Z.; Zhang, L.; Gao, Y.; Liu, H.; Hu, H. Bio-Inspired Icephobic Coatings for Aircraft Icing Mitigation: A Critical Review. Rev. Adhes. Adhes. 2020, 8, 2. 
153. Kim, P.; Wong, T.S.; Alvarenga, J.; Kreder, M.J.; Adorno-Martinez, W.E.; Aizenberg, J. Liquid-Infused Nanostructured Surfaces with Extreme Anti-Ice and Anti-Frost Performance. ACS Nano 2012, 6, 6569-6577. [CrossRef] [PubMed]

154. Yin, X.; Zhang, Y.; Wang, D.; Liu, Z.; Liu, Y.; Pei, X.; Yu, B.; Zhou, F. Integration of Self-Lubrication and Near-Infrared Photothermogenesis for Excellent Anti-Icing/Deicing Performance. Adv. Funct. Mater. 2015, 25, 4237-4245. [CrossRef]

155. Shen, Y.; Wu, Y.; Tao, J.; Zhu, C.; Chen, H.; Wu, Z.; Xie, Y. Spraying Fabrication of Durable and Transparent Coatings for Anti-Icing Application: Dynamic Water Repellency, Icing Delay, and Ice Adhesion. ACS Appl. Mater. Interfaces 2019, 11, 3590-3598. [CrossRef]

156. Zhuo, Y.; Hakonsen, V.; He, Z.; Xiao, S.; He, J.; Zhang, Z. Enhancing the Mechanical Durability of Icephobic Surfaces by Introducing Autonomous Self-Healing Function. ACS Appl. Mater. Interfaces 2018, 10, 11972-11978. [CrossRef]

157. Wang, Y.; Yao, X.; Wu, S.; Li, Q.; Lv, J.; Wang, J.; Jiang, L. Bioinspired Solid Organogel Materials with a Regenerable Sacrificial Alkane Surface Layer. Adv. Mater. 2017, 29, 170086. [CrossRef]

158. Shen, Y.; Wu, X.; Tao, J.; Zhu, C.; Lai, Y.; Chen, Z. Icephobic materials: Fundamentals, performance evaluation, and applications. Prog. Mater. Sci. 2019, 103, 509-557. [CrossRef]

159. Zhuo, Y.; Xiao, S.; Amirfazli, A.; He, J.; Zhang, Z. Polysiloxane as icephobic materials-The past, present and the future. Chem. Eng. J. 2021, 405, 127088. [CrossRef]

160. Huang, X.; Tepylo, N.; Pommier-Budinger, V.; Budinger, M.; Bonaccurso, E.; Villedieu, P.; Bennani, L. A survey of icephobic coatings and their potential use in a hybrid coating/active ice protection system for aerospace applications. Prog. Aerosp. Sci. 2019, 105, 74-97. [CrossRef]

161. Morita, K.; Kimura, S.; Sakaue, H. Hybrid System Combining Ice-Phobic Coating and Electrothermal Heating for Wing Ice Protection. Aerospace 2020, 7, 102. [CrossRef]

162. Pommier-Budinger, V.; Budinger, M.; Tepylo, N.; Huang, X. Analysis of piezoelectric ice protection systems combined with ice-phobic coatings. In Proceedings of the 8th AIAA Atmospheric and Space Environments Conference, Washington, DC, USA, 13-17 June 2016. 